NBER WORKING PAPER SERIES

\title{
AUTO-ENROLLMENT RETIREMENT PLANS FOR THE PEOPLE: CHOICES AND OUTCOMES IN OREGONSAVES
}

\author{
John Chalmers \\ Olivia S. Mitchell \\ Jonathan Reuter \\ Mingli Zhong \\ Working Paper 28469 \\ http://www.nber.org/papers/w28469
NATIONAL BUREAU OF ECONOMIC RESEARCH
1050 Massachusetts Avenue
Cambridge, MA 02138
February 2021

This research was supported by a grant from the US Social Security Administration (SSA) to the Michigan Retirement Research Center (MRRC) as part of the Retirement Research Consortium (RRC). Support was also provided by the Pension Research Council/Boettner Center of the Wharton School at the University of Pennsylvania; the Pew Foundation; the AARP; and the Quartet program at the University of Pennsylvania. We would like to thank Jeffrey Brown, Mark Iwry, David John, James Poterba, Geoffrey Sanzenbacher, and seminar participants at Brandeis, Rutgers, University of Arizona, University of Illinois, the 21th Social Security Administration Retirement and Disability Research Consortium Annual Meeting, and the NBER Conference on Incentives and Limitations of Employment Policies on Retirement Transitions, for their helpful comments. We thank many individuals from the OregonSaves program for numerous discussions and insights into the OregonSaves program, and Yong Yu as well as Wenliang Hou for excellent research assistance. The findings and conclusions are solely those of the authors and do not represent the views of SSA, any agency of the Federal Government, the MRRC, OregonSaves, any other institutions with which the authors are affiliated, or the National Bureau of Economic Research.

At least one co-author has disclosed additional relationships of potential relevance for this research. Further information is available online at http://www.nber.org/papers/w28469.ack

NBER working papers are circulated for discussion and comment purposes. They have not been peer-reviewed or been subject to the review by the NBER Board of Directors that accompanies official NBER publications.

(C) 2021 by John Chalmers, Olivia S. Mitchell, Jonathan Reuter, and Mingli Zhong. All rights reserved. Short sections of text, not to exceed two paragraphs, may be quoted without explicit permission provided that full credit, including (C) notice, is given to the source. 
Auto-Enrollment Retirement Plans for the People: Choices and Outcomes in OregonSaves John Chalmers, Olivia S. Mitchell, Jonathan Reuter, and Mingli Zhong

NBER Working Paper No. 28469

February 2021

JEL No. D14,G5,J26,J32

\begin{abstract}
Oregon recently launched an automatic-enrollment retirement savings program for private sector workers lacking access to other workplace retirement plans. We analyze participation choices, account balances, and inflow/outflow data using administrative records between August 2018 and April 2020. Within the small to mid-sized firms served by OregonSaves, estimated average aftertax earnings are low $(\$ 2,365$ per month) and turnover rates are high (38.2\% per year). Younger employees and employees in larger firms are less likely to opt out, but participation rates fall over time. The most common reason given for opting out is "I can't afford to save at this time," but the second most common is "I have my own retirement plan." As of April 2020, 67,731 accounts had positive account balances, holding $\$ 51.1$ million in total assets. The average balance is $\$ 754$, but with considerable dispersion; younger workers accumulating the fewest assets due to higher job turnover. Overall, we conclude that OregonSaves has meaningfully increased employee savings by reducing search costs. The $34.3 \%$ of workers with positive account balances in April 2020 is comparable to the marginal increase in participation at larger firms in the private sector. Employees opting out of OregonSaves are often doing so for rational reasons.

John Chalmers

Charles H. Lundquist College of Business

University of Oregon

Eugene, OR 97403

jchalmer@uoregon.edu

Olivia S. Mitchell

University of Pennsylvania

The Wharton School

3620 Locust Walk, St 3000 SH-DH

Philadelphia, PA 19104-6302

and NBER

mitchelo@wharton.upenn.edu

\author{
Jonathan Reuter \\ Carroll School of Management \\ Boston College \\ 224B Fulton Hall \\ 140 Commonwealth Avenue \\ Chestnut Hill, MA 02467 \\ and NBER \\ reuterj@bc.edu \\ Mingli Zhong \\ NBER \\ 1050 Massachusetts Avenue \\ Cambridge, MA 02138 \\ mzhong@nber.org
}




\section{Introduction}

Only about half of the U.S. private-sector workforce is currently covered by an employersponsored retirement plan, a fact that has sparked debate over whether there is a national “retirement crisis.” ${ }^{1}$ In response, a growing number of states has mandated that private-sector firms offer retirement saving accounts to their employees. ${ }^{2}$ Oregon was among the first, passing a bill in 2015 launching the mandatory OregonSaves program, which is structured as a Roth IRA with automatic enrollment. OregonSaves’ explicit goal is to boost workers’ personal retirement savings and thereby decrease dependency on Social Security and means-tested social transfers. ${ }^{3}$ In this paper, we examine who opted out of OregonSaves and why, how the program affected saving patterns for participating employees, and whether it seems likely to meaningfully increase retirement savings for participants.

A key rationale offered to justify state-based mandatory automatic enrollment retirement plans is that the vast majority of workers lacking access to employer-sponsored retirement plans has no dedicated retirement saving vehicles. ${ }^{4}$ According to the 2014 Summary of Income and Program Participation (SIPP), only 22.1\% of employees working at a firm without a pension plan had opened an IRA, and only 7.6\% were actively contributing. In other words, while workers who lack employer-sponsored retirement plans could respond by opening and funding their own Traditional or Roth IRAs, the vast majority do not, resulting in few accumulated retirement assets. Whether we should expect Oregon's state-sponsored retirement plan to significantly increase

\footnotetext{
${ }^{1}$ See Miller et al. (2015) and rebuttals by Biggs and Schieber (2015, 2019a, 2019b). Also see Bee and Mitchell (2017). ${ }^{2}$ OregonSaves and Illinois' Secure Choice began enrolling employees in 2017; California's CalSavers began enrolling employees in July 2019. As of December 2020, Colorado, Connecticut, Maryland, and New Jersey have also taken steps to offer a state-sponsored IRA featuring automatic enrollment.

${ }^{3}$ The program's official designation is the Oregon Retirement Savings Plan, referenced in the enabling legislation and Oregon Revised Statutes 178.200-178.245. See Belbase and Sanzenbacher (2018) and Bradford (2017) for additional discussion.

${ }^{4}$ See, for example, Gale and John (2018). Biggs (2016) notes some of the difficulties in measuring pension coverage in the U.S. workforce, depending on the dataset used.
} 
retirement savings among this population depends crucially on why workers are not already saving.

In what follows, we examine three non-mutually exclusive explanations for the dearth of employee-initiated retirement savings, which we refer to as the "search costs," "can't afford to save," and "don't need to save” hypotheses. The search costs hypothesis posits that the introduction of an automatic-enrollment retirement plan will increase the fraction of workers contributing to a retirement savings account by eliminating the search cost associated with learning about and enrolling in an IRA. ${ }^{5}$ Because prior research has shown that earnings, financial literacy, and the extent of retirement planning are positively correlated (e.g., Lusardi and Mitchell 2007; Clark et al. 2017), these search costs may be particularly large within the sample of workers targeted by OregonSaves. ${ }^{6}$ Furthermore, studies of participant behavior in employer-provided 401(k) plans find that the younger, lower-paid, and less educated workers are more likely to adopt default savings rates and invest through default investment options (e.g., Madrian and Shea 2001; Mitchell and Utkus 2012; Chalmers and Reuter 2020). Therefore, if search costs are a primary reason that many workers are not already saving for retirement, the introduction of an automaticenrollment retirement savings plan is likely to result in high participation rates at the default saving rate and significant incremental retirement savings. Evidence in Célerier and Matray (2019) that increased bank branch supply leads to greater wealth and net-worth accumulation in low-income households implies that supply-side solutions to low savings rates, such as OregonSaves, may lead to improved welfare.

A second hypothesis is that workers targeted by OregonSaves cannot afford to save for

\footnotetext{
5 Madrian and Shea (2001) were the first to demonstrate that the introduction of automatic enrollment could significantly increase participation rates within an existing single employer 401(k) plan.

${ }^{6}$ Carlin, et. al. (2013) make the theoretical argument that default features, similar to those in OregonSaves, that reduce search costs are likely to be welfare enhancing if participants are sufficiently homogeneous in their preferences.
} 
retirement. ${ }^{7}$ Many households report that they have difficulty meeting even basic expenses. For example, the Board of Governors of the Federal Reserve System (2019: page 21) found that "17 percent of adults expected to forgo payment on some of their bills in the month of the survey." Such statistics suggest that the marginal utility of consumption is high for many low-income workers, causing them rationally to prioritize consumption over retirement savings. The larger the fraction of workers who cannot afford to save, the lower the optimal participation rate, and the higher the expected opt out rate.

The third hypothesis for low pre-existing savings rates is that workers do not believe that additional savings will improve their welfare. Because Social Security benefit replacement rates are relatively high for low-income workers, lower-paid employees at firms lacking employersponsored retirement plans may rationally decide to consume more, rather than increasing their retirement savings. ${ }^{8}$ In addition, low-income workers may not intend ever to retire. Like those that cannot afford to save, employees who believe there is insufficient value to additional retirement savings are likely to opt out at high rates (as are the small fraction of employees who already contribute to an IRA).

The introduction of OregonSaves allows us to determine how workers who previously lacked access to workplace retirement plans respond when an automatic-enrollment retirement savings plan is introduced. While there have been numerous studies of automatic enrollment in

\footnotetext{
${ }^{7}$ For example, Bronchetti, et al. (2011) find that low income taxpayers receiving a tax refund are not substantially more likely to save their refund when saving is offered as opt out versus opt in. They do find, however, that savings take-up rates rise when refunds are larger.

${ }^{8}$ The CBO (2019: p. 18) finds that "replacement rate based on all earnings from age 22 through age 61 is 80 percent for workers born in the 1960s whose lifetime earnings fall in the lowest earnings quintile, more than double the 34 percent for workers whose earnings fall in the highest quintile." At the same time, it is not clear that lower income households accurately estimate their Social Security benefits. Gustman and Steinmeier (2005) find that knowledge of social security benefits is negatively correlated with lifetime income and wealth. For example, in the first and second lifetime income deciles, only $11.2 \%$ and $16.3 \%$ of respondents provide estimates of their Social Security Benefits that were between 75 and 125 percent of actual benefits.
} 
large firms offering 401(k) plans, we know little about whether such evidence will generalize to lower-income workers employed by smaller firms that do not offer their own retirement savings plans. ${ }^{9}$ Our analysis of individual-level administrative data thus sheds light on participation decisions, contribution rates, and the evolution of account balances, as well as the reasons that employees give for opting out of OregonSaves.

Importantly, these data allow us to examine the relative importance of our three hypotheses regarding why some workers do not save. If the low pre-existing levels of retirement saving are primarily due to high search costs, then we anticipate finding relatively high participation rates under OregonSaves and persistent contributions. In addition, since the program mandates a 5\% default saving rate, if this is perceived by OregonSaves participations to be a "recommended" savings rate, we expect little variation in observed savings rates. However, if low pre-existing levels of retirement saving are primarily due to workers' inability (or perceived lack of need) to save for retirement, then we anticipate finding low participation rates and low saving rates, especially among workers with lower and more volatile earnings profiles. ${ }^{10}$

Our analysis of account-level data from August 2018 through April 30, 2020 provides evidence that all three hypotheses play a role in participants' behavior. Consistent with the search cost hypothesis, OregonSaves is generating savings for a substantial number of employees: in fact, more than 67,700 employees accumulated over \$51 million dollars through April 2020 (and \$79.1 million through November 2020; CRR 2020). However, consistent with significant liquidity constraints, even our upper bound participation rate estimate of $62.4 \%$ is significantly below the

\footnotetext{
${ }^{9}$ Madrian and Shea (2001) and Stock and Wise (1990) focused on participant behavior within the retirement plan of a single large firm. Studies of participant behavior across multiple firms, such as Carroll et al. (2009) and Mitchell and Utkus (2012), have examined firms offering company-based 401(k) or 403(b) retirement plans.

${ }^{10}$ Carroll et al. (2009: 1668) pointed to the benefit of active decision-making with respect to savings rates under the assumption that desired savings rates likely vary across employees regardless of their financial literacy levels. Yet given evidence on the depth of financial illiteracy, they concluded that "[w]ell-chosen defaults are likely to be superior to active decisions in the asset allocation domain.”
} 
levels observed in studies of firm-sponsored 401(k) plans, likely reflecting our finding that employers targeted by OregonSaves are disproportionately in industries with lower wages, more volatile wages, and higher levels of job turnover. The lower bound estimated participation rate, based on those having a positive account balance, is $34.3 \% .{ }^{11}$ Furthermore, $30.3 \%$ of those who opt out say they do so because they "can't afford to save,” and the likelihood of stating this is significantly higher in those industries with lower average wages. The fact that OregonSaves is targeting a low-income population that has not traditionally been served by workplace retirement saving accounts in the United States argues against focusing solely on participation rates when evaluating its success. Indeed, in some cases, the welfare of low-income workers might be improved by opting out of the plan until their budget constraints relax.

Consistent with the “don’t need to save” hypothesis, $23.9 \%$ of those who opt out state that “I have my own retirement plan,” and this answer is relatively more likely among employees in higher-wage industries. While this is the second most common reason given for opting out, it suggests that only $9.7 \%$ of the workers targeted by OregonSaves have an existing IRA or 401(k) plan, versus $22.1 \%$ in the SIPP dataset. ${ }^{12}$ This difference likely arises from the fact that OregonSaves serves a lower-income population than is included by SIPP. It also suggests that there is relatively little scope for OregonSaves to crowd out existing retirement plan contributions.

To shed additional light on who is the most likely to participate in OregonSaves, we focus on the cross-section of employees three months after their initial eligibility date (which is determined by the month when their employer first provides their data to OregonSaves). We find

\footnotetext{
${ }^{11}$ Quinby, et al. (2020) use OregonSaves data for September 2018 to September 2019 to calculate participation rates. Their lower bound estimate (based on positive account balances) is 48 percent and their upper bound estimate (based on a positive saving rate) is 67 percent. In part, our rates are lower because all of their calculations condition on active employees at employers that have made at least one contribution into OregonSaves.

12 See Online Appendix Table 1 for a comparison between OregonSaves employees and the SIPP sample.
} 
that younger employees are less likely to opt out, as are employees who have already been exposed to OregonSaves through a prior job, who work in larger firms, and who work at firms that have already made payroll contributions to OregonSaves. ${ }^{13}$ Conversely, and consistent with perceived liquidity constraints, opt out rates are higher when the local unemployment rate is higher, or when our industry-level measure of income volatility is higher. Employees who are terminated are less likely to opt out but also less likely to accumulate any assets during this three-month window, a phenomenon that drives a wedge between formal opt out rates and participation rates inferred from positive account balances.

While there has been a steady increase in assets under management, there is considerable dispersion in OregonSaves account balances. When we focus on the set of employees with at least one contribution into OregonSaves, the average account balance is $\$ 754$, and the average monthly account-level inflow is $\$ 117$. Yet the fraction of accounts with any inflows falls from $65.6 \%$ in August 2018 to 34.4\% in April 2020, a pattern which is largely driven by job turnover. Monthly account-level outflows are far less common (impacting 2-3\% of accounts per month), but they are much larger in magnitude. The average outflow rose from \$355 in August 2018 to \$590 in April 2020. ${ }^{14}$ When we compare employees who are classified by their employers as being active in month $t$, to those who are not, we find predictable differences in asset accumulation. Employees active 18 months after their initial contribution have an average account balance of $\$ 1,132$ (including \$0s), versus $\$ 370$ for those classified as inactive. The fact that the youngest employees (age 18-25) are the least likely to remain active explains why they accumulate the least assets ( $\$ 487$ at month 18 , versus $\$ 980$ to $\$ 1,186$ for those age $36-75$ ). While our ability to measure the

\footnotetext{
${ }^{13}$ About half of the firms in our sample have not initiated payroll transfers to OregonSaves.

${ }^{14}$ The Roth IRA and modest earnings on the default money market fund for the first $\$ 1,000$ of investments reduces tax implications of withdrawals.
} 
impact of COVID-19 related economic shocks is limited by the fact that our data end in April 2020, we do find a 13.9\% drop in the likelihood of any inflows in April 2020. This drop is consistent with large job losses that month not yet reflected in the employee job status variable. More generally, we find that the likelihood of withdrawals spike following job turnover, suggesting that withdrawals from OregonSaves are used to smooth consumption. ${ }^{15}$

Overall, we conclude that OregonSaves has meaningfully increased employee savings by reducing search costs. The 34.3\% of workers with positive account balances in April 2020 is comparable to the marginal increase in participation of around 30\% in the large firm examined by Madrian and Shea (2001). Nevertheless, there are significant constraints to the savings that autoenrollment savings plans can achieve when provided to workers in industries and firms with low wages, volatile wages, and high turnover. Our evidence suggests that employees who are opting out of OregonSaves are often doing so for rational reasons.

\section{Institutional Details}

OregonSaves is structured as a Roth Individual Retirement Account (IRA) with automatic enrollment and a default after-tax contribution rate of 5\%. Although similar to privately-managed employer-sponsored 401(k) and 403(b) retirement plans, there are four important differences. First, all private-sector firms without existing employer-sponsored retirement plans are required to enroll their employees in the state-sponsored plan. Second, unlike most plans featuring automatic enrollment, there is no scope for an employer match; contributions are limited to those made by the employee. Third, when a worker moves from one OregonSaves-participating employer to another, contributions flow to the same account, reducing the likelihood of multiple

\footnotetext{
${ }^{15}$ Quinby, et. al. (2020) use data for September 2018 to September 2019 to classify participants into five categories. They find that the probability of any outflows is highest among the subset of "job changers."
} 
accounts with small balances. Fourth, by default, the first \$1,000 deposited into the OregonSaves account is invested in a money market fund, with contributions above that threshold automatically invested in an age-based target date fund (TDF). One appealing feature of this plan design is that participants can access a substantial portion of their money without risk of tax penalty, allowing OregonSaves to function as both a liquid savings account and a retirement savings plan. ${ }^{16}$

While the default saving rate in OregonSaves is $5 \%$ of each paycheck, participants may select any (integer) contribution rate between $0 \%$ and $100 \% .{ }^{17}$ In addition, OregonSaves features automatic escalation, with the saving rate increasing by 1 percentage point on January of each calendar year, up to a maximum of 10 percent. Participants may override the default asset allocation scheme by selecting any investment(s) from the state-determined menu which includes a money market fund, a suite of target date funds, and the State Street Equity 500 Index Fund.

The OregonSaves program was rolled out to employers in seven waves. The first wave consisted of firms volunteering to be in the pilot program, followed by six compulsory waves of decreasing employer size. The largest firms (100+ employees) began the compulsory registration period on October 1, 2017. The smallest firms (4 or fewer employees) were scheduled to start enrolling May 12, 2020, but the deadline was then pushed to January 15, 2021, due to the COVID19 pandemic. Nevertheless, smaller firms were allowed to register employees before their official wave and, because of the lack penalties for non-participation, some large, reluctant employers may still have not registered. ${ }^{18}$

\footnotetext{
${ }^{16}$ As with other Roth IRAs, participants can withdraw contributions (but not investment returns) without penalty up to age $59 \frac{1}{2}$, or in the event of a qualifying disability or for first-time home buyers.

${ }^{17}$ Up to the legal limit for Roth IRA contributions, which in 2019 were $\$ 6,000$ per year (or $\$ 7,000$ for those age $50+$ ); OregonSaves (2019).

${ }^{18}$ Firms which offer their own retirement plans are exempted from the mandate to offer the OregonSaves platform. All other employers are required to register, though penalties for failing to register were to be implemented from January 2020 (later postponed due to the pandemic). According to Senate Bill 164, "the Commissioner of the Bureau of Labor and Industries may assess against an employer who has engaged in an unlawful practice under section 2 of this 2019 Act a civil penalty in an amount up to $\$ 100$ for each employee who is eligible to participate in the plan
} 
OregonSaves provides employers with a pre-designed plan and safe harbor from fiduciary responsibility, thereby reducing set-up and monitoring costs. ${ }^{19}$ Once an employer is registered, it submits employee names, social security numbers, and dates of birth to OregonSaves, which commences a 30-day enrollment period. If an employee does not opt out during the first 15 days, OregonSaves attempts to verify her tax identification number and, if successful, opens an individual Roth IRA for her at the end of the 30-day window. At that point, employers can direct contributions to OregonSaves. After registering, employers are also able to provide updates to participants’ employment status to the OregonSaves administrator.

\section{OregonSaves Participant and Plan Statistics}

In this section, we present summary statistics for OregonSaves-covered employers and employees. We have obtained anonymized individual-level monthly administrative data for all workers who had access to the program through April 2020, including workers who opted out of OregonSaves during the enrollment window, those who stopped contributing before the end of our sample period, and those who have yet to contribute. The dataset includes employee-level information on age, saving rates, and employer, as well as account-level information on monthly contributions and withdrawals and asset allocation. ${ }^{20}$ We also possess employer-level information on industry and firm size, and the date on which each employer first directs employee contributions to OregonSaves. ${ }^{21}$

\footnotetext{
developed under ORS 178.205, not to exceed an aggregate amount of \$5,000 in a calendar year.” Senate Bill 164 was signed into law by Governor Kate Brown on May 22, 2019.

See https://olis.leg.state.or.us/liz/2019R1/Downloads/MeasureDocument/SB164/Enrolled.

${ }_{19}$ Scott and Hines (2020) survey OregonSaves’ participating employers and find that approximately $80 \%$ of participating employers report no out of pocket costs associated with the program.

${ }^{20}$ In this section, our unit of observation is the employer-employee pair. Because individual employees can be enrolled into OregonSaves by multiple employers, they can be assigned multiple employee identification codes; however, they can only have one OregonSaves account.

${ }^{21}$ Because our data are derived from a number of sources including information entered by employers, employees, and the record keeper, there are inevitably data entry errors. Our analysis filters out approximately 800 individual
} 
Table 1 shows the total number of employers and employer-employee pairs covered by the OregonSaves program. Column (1) presents the cumulative number of employers that uploaded employee information to the OregonSaves administrator by the end of each month between August 2018 and April 2020. Column (2) presents the subset of employers that processed payroll for at least one employee by the end of each month. By the end of April 2020, 11,088 employers had registered their employees with OregonSaves, but only 5,537 had directed any contributions to OregonSaves. Some portion of this gap can be explained by the fact that processing payroll takes time and many employers registered at the end of 2019.

\section{Table 1 here}

Column (3) reports the cumulative number of employees whose names had been provided by their employers to the OregonSaves administrators. Approximately 289,657 employees have engaged at some level with OregonSaves by the end of our sample period, including employees who opted out of the program. Column (4) reports the subset of employees whose employers have directed a contribution to OregonSaves, showing that by April 2020, 226,178 employees are working (or were previously working) at employers that processed OregonSaves contributions for at least one employee. By comparing columns (1) and (2) in April 2020, we observe that approximately half of all employers have not processed payroll. However, by comparing columns (3) and (4) in April 2020, we see that nearly 80\% of all registered employees work at employers that have begun directing employee contributions to OregonSaves, thus making positive account balances possible.

Column (5) reports the cumulative number of employees classified by the administrator as both eligible to participate and actively working. Employees are eligible to participate if the initial 
30-day enrollment window closes and their identities are verified. The administrator includes a flag indicating whether an employee is active or inactive in month $t$. For over $93 \%$ of the employeemonths classified as inactive, we observe a reason that the employee is inactive (e.g., terminated, seasonal layoff, or deceased). Because the administrator only updates an employee's status when an employer updates it with OregonSaves, the sample of eligible and active employees almost certainly overstates the number of employees still employed in month $t$. Column (6) reports the cumulative number of eligible and active employees whose employers have processed contributions, which is the maximum number of employees who could feasibly contribute to OregonSaves each month.

Column (7) reports the cumulative number of employees with a positive account balance at the end of each month, while column (8) reports the cumulative number of employees with an open account in month $t$ with a positive account balance during any portion of our sample period (even if the positive balance occurs after month $t$ ). The difference of 8,728 between columns (7) and (8) in April 2020 represents the number of employee-employer pairs that made contributions into OregonSaves but subsequently withdrew their entire balances. ${ }^{22}$

A common measure of retirement plan efficacy is the participation rate. Madrian and Shea (2001) reported that automatic enrollment in one large 401(k) plan of a large relatively high-wage firm resulted in a participation rate of $85.9 \%$, with the largest increases being for younger, lowerincome workers. Mindful of the fact that we are measuring participation rates in a set of firms having lower pay and higher turnover, we offer two different measures of participation in Table 1. The Global Participation Rate is the number of employees with current positive account balances

\footnotetext{
${ }^{22}$ Note that the totals in columns (7) and (8) slightly overstate the total number of unique accounts. This is because a participant who works for two different employers during our sample period will appear as two employee-employer pairs, but the participant makes all contributions into a single OregonSaves account.
} 
(column (7)) divided by the total number of employees ever entered into the OregonSaves system by employers who processed payroll (column (4)). The Global Participation Rate is 34.3\% at the end of our sample period. The Global Participation Rate decreases as more employees formally opt out, as more employees set their savings rate to zero, as more employees become inactive due to job turnover, and as more employees who previously contributed into OregonSaves withdraw their account balances.

Our second measure is the Feasible Participation Rate, defined as the number of employees who have a positive account balance at some point during our sample period (column (8)) divided by the number of number of active, eligible employees working at employers who already processed contributions (column (6)). Thus, the Feasible Participation Rate measures the proportion of employees that could, with near certainty, show up as participants in OregonSaves since they are active, eligible, and are with an employer directing contributions to OregonSaves. The Feasible Participation Rate is $62.4 \%$ at the end of our sample period. While both participation rates are considerably lower than the $85.9 \%$ estimated by Madrian and Shea (2001), they represent significant increases relative to the counterfactual participation rates within the population of lowincome workers targeted by OregonSaves, which are arguably close to zero. If we assume that the marginal impact of OregonSaves on retirement participation is on the order of $30 \%$, this is similar in magnitude to the average causal estimate of the impact of automatic enrollment in Madrian and Shea, despite the absence of any employer match.

Table 2 presents employee-level summary statistics by industry, using panel data through April 2020. Columns (1) and (2) show the number of employees by industry and the number of eligible and active employees working at firms that have processed payroll. The largest industries represented in OregonSaves are food services, business support, health care, and retail trade. It is 
our understanding that a large number of the health care workers can best be described as homehealth care workers.

Table 2 here

We report summary statistics in columns (3) through (11) for the entire sample of 289,657 employee-employer pairs. Age is defined as the calendar year in which the employee first appears in the administrative data minus the stated year of birth. We report the mean, median, and interquartile ( $25^{\text {th }}$ to $\left.75^{\text {th }}\right)$ range. The average age for employees who had access to OregonSaves (including participants and those who opted out) is 36 (median is 33).

Two measures of job turnover rates are provided. Annual turnover equals one if the employee was classified as "terminated," on "seasonal layoff,” or “out of business,” 12 months after becoming eligible to contribute (based on one observation per employee with at least 12 months of OregonSaves administrative data). Similarly, monthly turnover equals one if the employee was "active” in month $t-1$ but classified as "terminated,” on "seasonal layoff,” or "out of business" in month $t$ (where the unit of observations is now employee-employer-month). The classification of employees' job status is provided to the administrator by employers. To the extent that employers fail to update job status in a timely manner, our estimated turnover rates will understate actual turnover rates. ${ }^{23}$ Despite this caveat, there is a positive correlation between the number of employees within each industry and the turnover rate, which suggests OregonSaves covers many contingent and temporary workers who usually lack access to employment-based defined contribution plans.

We estimate monthly after-tax earnings at the employee-month level as the total monthly contributions divided by the current savings rate (e.g., \$100 after-tax contribution divided by 5\%

\footnotetext{
${ }^{23}$ In unreported results, we find employers that have not yet processed payroll are significantly less likely to report any changes in employee status.
} 
implies \$2,000 in after-tax income). Monthly earnings can be estimated only for the subset of employees who made positive contributions to their accounts. The mean, median, and interquartile range within the full sample are $\$ 2,365, \$ 1,883$, and $\$ 1,960$, respectively. Employees in the largest industries represented in OregonSaves, such as business support, food services, and health care, have monthly earnings lower than the average of the entire OregonSaves workforce. The correlation between industry-level monthly turnover rates and industry-level mean monthly earnings is -0.52, implying that lower-income jobs have higher turnover rates. Finally, we report the within-employee standard deviation of monthly earnings, calculated at the employee level using all months with positive contributions within each employee-employer pair (i.e., we exclude any months without contributions). The average per person monthly volatility of earnings is $\$ 945$, or nearly half the mean after-tax earnings of $\$ 2,365$. This high level of volatility illustrates that the average participant in OregonSaves faces substantial monthly income uncertainty.

\section{Cross-sectional Evidence on OregonSaves Opt Out Rates and Account Balances}

Having shown that OregonSaves is extending access to the new savings plan to workers in low-income, high-turnover industries, we next analyze opt out decisions. If the "search cost" hypothesis dominates, we expect to find low opt out rates, aside from those who already have a retirement savings plan. Under the “can’t afford to save” and “don’t need to save” hypotheses, we expect to observe higher opt out rates among employees in industries with lower wages and higher turnover. $^{24}$

In Table 3, we focus on each employee three months after her initial month of eligibility, which is defined as the first month in which she would become eligible to contribute into

\footnotetext{
${ }^{24}$ The fact that we cannot measure income unless an employee contributes to OregonSaves prompts us to focus on industry-level income measures.
} 
OregonSaves if she has not formally opted out, is still employed, and has had her identity successfully verified. ${ }^{25}$ The total number of employees reported in column (1) is lower than Tables 1 and 2 because the relevant month for some employees is before August 2018 or after April 2020.

\section{Table 3 here}

Column (2) reports that, on average, 40.9\% of employees formally opt out of OregonSaves within three months of their initial eligibility dates. The correlation between the industry-level opt out rate and the mean industry-level earnings in Table 2 is 0.73 , suggesting that industries with higher earnings levels are more likely to opt out of OregonSaves. While this correlation is broadly consistent with evidence that lower-paid employees are more likely to accept default options (as in Chalmers and Reuter, 2020, and Mitchell and Utkus, 2012), it runs counter to the “can’t afford to save” hypothesis.

At our request, the administrator asked employees who formally opted out to provide a reason for doing so. Conditional on opting out, 30.3\% of employees respond that they cannot afford to save, while $25.9 \%$ say that they already have a retirement plan. The across-industry correlation between "can't afford to save" and mean earnings is -0.52 , while the across-industry correlation between "already have a plan" and mean earnings is 0.24 . In other words, conditional on opting out, employees in lower-paying industries are more likely to cite lack of income and less likely to cite having an existing retirement account.

In addition to summarizing the fraction of employees who formally opt out, we also use account balances at the same point in time to shed light on participation rates. Columns (5) through (7) report the fractions of all employees lacking an account, having an open account with a balance

\footnotetext{
${ }^{25}$ In Online Appendix Table 2, we document that the formal opt out rate does not change significantly after month three. In Online Appendix Table 3, we report the month three opt out rate separately for each month. It is slightly higher at the end of our sample period than at the beginning.
} 
of $\$ 0$, and having an open account with a positive balance, respectively. Overall, the fraction of employees with no account three months after their initial eligibility date is $71.9 \%$. This includes people who opt out, cannot have their identities verified, are no longer employed when the employer begins directing contributions to OregonSaves, or are employed by a firm that has not begun directing contributions to OregonSaves. Of the remaining employees, $26.7 \%$ have a positive balance and $1.4 \%$ have a $\$ 0$ balance.

The remaining columns report the mean, median, and interquartile range of the account balance for the subset of employees with positive account balances three months after becoming eligible to contribute. Average balances after three months of eligibility range from a low of \$192 for workers in the Arts/Entertainment sector, to a high of $\$ 462$ for Professional/Scientific employees. Unsurprisingly, the across-industry correlation between average account balances and mean industry earnings from Table 2 is 0.92 , which is consistent with employees in higher-paying industries making larger monthly contributions.

Table 4 summarizes the reasons that employees give for opting out from OregonSaves using the full sample rather than conditioning on the third month after registration. The top panel focuses on the options that employees were offered in our survey. Again, the most common reason cited for opting out is “I can’t afford to save at this time” (28.6\% of all employees) and the second most common reason is "I have my own retirement plan" (23.9\%). The third most common is "Other," but with no additional details. The fourth most common is "I'm not interested in contributing through this employer.” which may indicate that the employee is working a part time or second job, or that the employee is not currently interested in saving for retirement. The bottom panel summarizes the open responses, which we manually assigned to a handful of categories. Here, the most popular responses could be summarized as "Not interested.” There were a number 
of responses related to eligibility (e.g., "I am no longer employed there” or "I will be leaving Oregon soon" or "I am too young to participate”) or the need for the program ("I am already retired” or "This is temporary work”). Slightly less than 1 percent objected to being automatically enrolled in the plan, and slightly less than 0.1 percent objected to the level of fees.

\section{Table 4 here}

If we assume that all OregonSaves-eligible workers with an existing retirement plan opt out of OregonSaves, then the $23.9 \%$ of respondents saying they have their own retirement plan implies that $9.7 \%$ (equals $23.9 \%$ times 117,345 divided by 289,657 ) of OregonSaves’ population already have an IRA or employer-sponsored retirement account. If we assume that only half of the workers with an existing retirement plan opt out, the fraction doubles to $19.4 \%$, and it is still below the $22.1 \%$ implied by the 2014 SIPP. In either case, it is clear that a large majority of potential participants is unlikely to be saving for retirement outside of OregonSaves.

To explore heterogeneity in employee behavior regarding participation and account balances, we estimate a series of linear probability models. In Table 5, the dependent variable equals 100 if employee $i$ formally opted out of OregonSaves within three months of the initial eligibility date, and zero otherwise, allowing us to interpret coefficients as increases in percentage points. Employee-level controls include age dummies (the reference group is age 18-25); account holder location indicators (the reference group is living in an urban Oregon zip code); dummy variables indicating whether this is the second or third (or more) time that the individual worked at an OregonSaves-covered employer; and an indicator of whether the employee terminated in or before month $t$. In all but one specification, we also control for the average unemployment rate over the prior three months in the Oregon (or Washington) county corresponding to the accountlevel mailing address. Employer-level independent variables include firm size (measured as the 
natural logarithm of the number of employees in the month that the firm joins OregonSaves) and variables indicating whether the employer joined OregonSaves during the pilot phase; whether the employer registered after the OregonSaves deadline based on its firm size; and whether the employer had processed contributions for at least one employee through month $t$. Industry-level controls include median employee earnings within the industry in month $t$ (as inferred by us) and the standard deviation of employee earnings within the industry in month $t$. Standard errors are clustered by employer.

\section{Table 5 here}

The first column is restricted to employees who live in Oregon or Washington, allowing us to control for the average unemployment rate in the employee's county over the prior three months. Column (2) includes an additional 4,520 employees who live outside of Oregon and Washington but are covered by OregonSaves, likely because their employers are based in Oregon. Columns (3) and (4) include industry fixed effects. Column (4) also includes the fraction of employee $i$ 's coworkers that had formally opted out as of month $t-1$. Column (5) replaces the industry fixed effects with firm fixed effects and drops any employer characteristics that are timeinvariant, as well as the industry income measures. All columns include year-month fixed effects. Across all specifications, we find that older workers are significantly more likely to opt out than their younger counterparts. One interpretation is that older workers are more likely than younger workers to have their own retirement plans, reducing the need for additional savings. Another interpretation is that, because they are closer to retirement, they perceive less benefit from beginning to save. We also find that employees with prior exposure to OregonSaves are less likely to opt out, perhaps because they come to recognize the value of a portable retirement plan. Additionally, employees who terminate during the three months after the initial eligibility date are 
much less likely to opt out, presumably because they see no need to opt out of a plan affiliated with an employer from whom they are no longer earning an income. The implication is that terminated workers will neither opt out from OregonSaves nor accumulate any savings.

With respect to employer characteristics, we find that employees in larger businesses are less likely to opt out. Employees working at employers that participated in the pilot program are also less likely to opt out, presumably because these employers were the most enthusiastic about introducing their employees to the OregonSaves program. Finally, employees whose employers demonstrate a level of cooperation with OregonSaves by processing contributions are generally less likely to opt out. The exception is that the coefficient becomes positive and marginally significant (at the 10-percent level) when we include employer fixed effects, suggesting that workers hired after the pilot-program employer begins processing payroll are more likely to opt out than the initial set of workers enrolled in OregonSaves.

As we found above, employees in industries with higher earnings (e.g., "Finance and Insurance” and “Information”) are also more likely to opt out. To the extent that they are already saving for retirement or have a concrete plan for doing so in the future, they have less need for a program like OregonSaves. At the same time, consistent with financial constraints, employees in industries with more volatile income (e.g., “Agriculture,” “Construction,” and "Real Estate”), and who live in counties with higher unemployment rates, are more likely to opt out. Neither income nor its volatility has explanatory power when we include industry fixed effects, suggesting that the relevant variation is across industry rather than within industry.

When we include the fraction of employees opting out at an employer in the prior month, we find a large significantly positive coefficient, and the $\mathrm{R}^{2}$ jumps from 0.104 to 0.275 . One interpretation is that employees are influenced by their peers’ opt out decisions. A non-mutually 
exclusive interpretation is that employers are influencing the opt out rate directly, perhaps by highlighting what they perceive to be problems with the program.

While Table 5 sheds light on the formal participation decision, it does not shed direct light on the accumulation of retirement assets, which is the ultimate goal of OregonSaves. Therefore, in Table 6, we use a similar set of linear probability models to predict positive account balances. The dependent variable equals 100 if an employee has a positive account balance three months after his initial eligibility date, and zero otherwise. Column (1) focuses on the 126,778 employees who live in Oregon or Washington and have not formally opted out through month three. ${ }^{26}$ The remaining columns are limited to employees whose employers have processed contributions. The independent variables and fixed effects mirror Table 5. Column (4) includes the fraction of employee’s coworkers with a positive account balance in the previous month.

\section{Table 6 here}

Several of the findings here are consistent with those in Table 5. Older workers and workers in industries with higher median incomes are more likely to opt out, and less likely to have a positive balance. Similarly, workers being exposed to OregonSaves through a second job are less likely to opt out and more likely to have a positive balance. Nevertheless, many of the other findings are at odds. Employees at larger firms, employees living outside of Oregon, and employees at firms that participated in the pilot program are all less likely to opt out, but conditional on not opting out, are also less likely to hold a positive account balance. The same is true for employees that terminate before the end of the three-month window. In fact, the majority of employees neither opts out nor has a positive account balance within three months of eligibility.

\footnotetext{
${ }^{26}$ By conditioning on not having formally opted out by month three, we are excluding some employees with positive account balances. However, the fraction of employees who do not opt out and have positive account balance is $42.5 \%$, while the fraction who do opt out and have a positive account balance is only $5.3 \%$.
} 
In part, this reflects the large number of employers that has not processed payroll for any of their employees, and, in part, it reflects employee turnover and withdrawals. However, the fact that pilot employers sought to participate in OregonSaves before they were required to do so makes the lack of positive account balances among employees hired after the pilot program all the more puzzling.

At firms that processed payroll for employees, the employees are significantly more likely to have a positive account balance, a result that is largely mechanical. In column (4), we observe that positive account balances are strongly predicted by the proportion of positive balance accounts at the participant's employer in the prior month. As in Table 5, this estimate could be driven by peer effects, in concert with transparent or opaque employer influences on employees' participation.

Overall, the findings in this section provide support for all three of the hypotheses that we offered at the outset to explain low retirement savings rates. Consistent with search costs, we find much higher participant rates among younger workers (who are likely less financially literate) and those being exposed to the OregonSaves program for the second or third time. Moreover, while our estimated participation rate ranges from $34.3 \%$ to $62.4 \%$, it is important to remember that OregonSaves is targeting workers without access to a traditional employer-sponsored retirement plan, for whom the baseline retirement saving rate is near $0 \%$. The hypothesis that low savings rates occur because people can't afford to save also finds support. Opt out rates are increasing in the local unemployment rate and the volatility of industry income, and employees in industries with lower earnings are more likely to state that they cannot afford to save when opting out. In some sense, these opt out choices are reassuring, because they likely reflect an optimal decision to prioritize current consumption (for which the marginal utility is high) over savings. Finally, the behavior of older workers and workers in industries with higher income levels are both potentially 
consistent with the “don’t need to save” hypothesis. Older participants may have a more precise estimate of the social security replacement rate they will face at retirement, reducing the perceived value of participating in OregonSaves, and workers in higher income industries are the most likely to have a preexisting retirement savings plan.

\section{Evolution of Saving Rates}

Turning to the distribution of saving rates, columns (1) and (2) of Table 7 again focus on employees three months after their initial eligibility month. Column (1) presents the distribution of contribution rates for all employees, including those who opted out of the program (for whom the saving rate is coded as $0 \%$ ). We see that over $98 \%$ of employees have a saving rate of either $0 \%$ or $5 \%$. Column (2) excludes employees who have formally opted out. The fact that $3.9 \%$ of employees still have a saving rate of $0 \%$ implies that some employees informally opt out by setting their saving rate to $0 \%$ without ever formally notifying their employers that they are opting out. In columns (3) and (4), we examine the contribution rate for each employee-employer pair in each month, allowing us to incorporate information on saving rates in sample months after month three. Column (3) focuses on all employees, while column (4) focuses on employees who are active, eligible, have an open account, and have not formally opted out in month $t$. Comparing columns (2) and (4), we observe a decrease in the fraction of employees with a saving rate of $5 \%$ and an increase in the fractions with saving rates of $0 \%, 6 \%$, and $7 \%$. The increased use of $6 \%$ and $7 \%$ saving rates is particularly noticeable in column (4), reflecting the impact of automatic escalation of $1 \%$ additional saving, implemented every January.

\section{Table 7 here}

Table 8 illustrates how contribution rates change from month to month. We focus on employees who are active, eligible, have an open account, and have not formally opted out in that 
month (the sample in column (4) of Table 7). For each employee-employer-month, we create the pair (contribution rates at month $t$-1, contribution rate at month $t$ ) ${ }^{27}$ We then tabulate the number of pairs in each bin of the matrix with the current rate on the horizontal axis and the lagged contribution rate on the vertical axis. As expected, the diagonal of this matrix contains the largest number of participant month observations, implying that saving rate decisions are extremely sticky. Overall, the last two columns of Table 7 show that $2.8 \%$ of participant-months involve a contribution rate increase versus $2.0 \%$ that involve a decrease; much of this difference can be attributed to the automatic escalation feature of OregonSaves. Specifically, there are 23,394 cases where the saving rate rises from $5 \%$ to $6 \%$, and another 5,204 cases where it increases from $6 \%$ to $7 \% .^{28}$ In other words, while opt out rates are significantly higher in our sample than for higherpaid employees of larger firms, the vast majority of those who do not opt out accept both the default saving rate and automatic escalation. Tables 7 and 8 are largely consistent with the search costs hypothesis, in that participants are willing to accept the default saving rate, conditional on participation. For those participants who do not wish to participate, there is clear evidence that they are capable of reducing their saving rates to zero.

In sum, then, and consistent with prior research on the stickiness of default saving rates (e.g., Madrian and Shea 2001), we find that the vast majority of participating employees saves at the $5 \%$ default rate. Savings rates of $6 \%$ and $7 \%$ appear to be driven almost entirely driven by automatic escalation. In other words, we observe far more variation along the extensive margin (opting out) than along the intensive margin (saving rate).

\footnotetext{
${ }^{27}$ We combine all contribution rates greater than $7 \%$ into a single category, as only a small fraction of people elect a rate higher than $7 \%$ over the period we examine.

${ }^{28}$ In Online Appendix Table 4, we show that rate increases are clustered on January 2019 and January 2020, the months in which automatic escalation applies.
} 


\section{Evolution of Account Balances}

We conclude by exploring the dynamics of flows into and out of OregonSaves accounts. Table 9 and Figure 1 summarize the substantial growth of OregonSaves over our sample period. In August 2018, there were $\$ 6.7$ million in assets and $86.4 \%$ of all dollars were invested in the default money market fund. While there have been steady outflows, they remain small relative to inflows, resulting in positive net inflows throughout the sample period. By April 2020, assets under management had grown to $\$ 51.0$ million, and $58.1 \%$ of assets were invested in the money market fund. In November 2020 (outside of our sample period), total assets exceeded \$79.1 million. The relatively high dollar outflows in the first quarter of 2020 may reflect concerns about COVID-19, but measured as a percent of assets, they are only slightly above average. The most striking change is the drop in total inflows in April 2020, which may reflect a sudden decline in earnings due to job loss.

\section{Table 9 and Figure 1 here}

Table 10 focuses on account-level balances, inflows, and outflows. The number of open accounts increases more than 300\% (from 19,078 to 77,007), while the number of open accounts with positive balances increases $280 \%$ (from 17,830 to 67,731 ). At the end of our study period, the average (positive) account balance is $\$ 754$. The average net (non-zero) flow each month is $\$ 90$, and the average inflow is $\$ 117$. Outflows are far less common, but they are much larger in magnitude. The average outflow is $\$ 517$. We plot monthly net flows, inflows, and outflows in Figure 1B. The rightmost column of Table 10 calculates the equal-weighted average asset allocation to the money market fund. Although 58.1\% of OregonSaves' plan dollars are invested in the money market fund, when we place equal weight on each account, the fraction rises to $86.2 \%$, because relatively few accounts have balances over $\$ 1,000$. This finding begs the question 
of whether it is desirable to default the first $\$ 1,000$ into the money market fund. If the long-term goal is to allow participants to benefit from the market risk premium, an alternative design might transfer assets from the money market fund to an age-appropriate TDF after a prescribed period of time (e.g., three months). ${ }^{29}$ By contrast, if the goal were simply to provide an emergency savings account that participants could use to smooth consumption, retaining the account in safe investments would be a reasonable default.

\section{Table 10 here}

Table 10 also illustrates the contrast between relatively stable outflows and the declining percentage of accounts with inflows over the sample period. Not surprisingly, the biggest drop in inflows occurs between March and April of 2020, when the economic effects of COVID closures were first enacted in Oregon. The general decline in the fraction of accounts with inflows is to be expected, since accounts enter our sample when an employment relationship begins and remain open without additional inflows when an employee is terminated or quits. However, to the extent that the portability features of OregonSaves are effective, the decline in inflows to accounts over time may be attenuated if employees move from one OregonSaves-participating employer to another.

In Figure 2A, we focus on employees who made at least one contribution into OregonSaves and who remain in our dataset for at least 3, 6, 12, or 18 months. We then plot the fraction of these participants making at least one contribution, contributions in two or more months, contributions in three or more months, etc. By construction, $100 \%$ of the participants make at least one contribution. Over a three-month horizon, the probability of three consecutive contributions is $70 \%$. When the horizon increases to six months, the probability of at least three contributions

\footnotetext{
${ }^{29}$ Online Appendix Table 5 reports the fraction of plan assets invested in each fund and Online Appendix Table 6 summarizes monthly returns and flows.
} 
increases to $77 \%$, but the probability of six consecutive contributions drops to $49 \%$. Similarly, the probability of at least six contributions increases to $61 \%$ when the horizon rises to 12 months, but the probability of 12 consecutive contributions is only $30 \%$. These patterns suggest either that a significant fraction of employees is opting out during the first 12 months in the program, or that their employment status is fluid.

\section{Figure 2 here}

In Figure 2B, we focus on 6,053 employees who made at least one OregonSaves contribution and who remain in our sample for at least 18 months. We plot the fraction of participants classified as inactive in month $t$, the fraction with a saving rate of $0 \%$, and the fraction classified as inactive or with a saving rate of $0 \%$. The fraction classified as inactive rises from $4 \%$ (in the month of the initial contribution) to $38 \%$ in month 18 , while the fraction with a saving rate of $0 \%$ rises from $6 \%$ to $21 \%$. In other words, the fraction of employees able to contribute to OregonSaves through their employers is declining monotonically. The fact that $4 \%$ of the employees are classified as inactive in the same month that they make their first contribution into OregonSaves speaks to the high turnover rates. The fact that $6 \%$ of the employees have a saving rate of $0 \%$ at the end of the month may reflect a decision to opt out in response to a reduced paycheck.

In Tables 11 and 12, we document the significant impact of employee turnover rates on OregonSaves account balances. The unit of observation is account $i$ in month $t$, and the sample is limited to the 59,043 participants who make at least one contribution into OregonSaves during our sample period. (We exclude anyone with a positive account balance in July 2018.) Table 11 reports the number of open accounts, fraction with a positive balance, fraction with any inflow or outflow, and average account balance (including zeroes), separately for employees classified as active 
versus inactive. The fraction of accounts in which the employee is classified as active by at least one OregonSaves-covered employer falls from $96.8 \%$ in month one, to $61.5 \%$ in month 18 . Among those classified as active, the average balance increases from $\$ 89$ to $\$ 1,132$, while the fraction of accounts with positive inflows decreases from $99.9 \%$ to $48.1 \%$. The likelihood of any outflow averages around $2.9 \%$. The fact that the likelihood of inflows falls below $50 \%$ within a sample of employees classified as active strongly suggests that the employee status flag is either not being updated by all employers, not being updated in a timely fashion, or both.

\section{Tables 11 and 12 here}

Among those classified as inactive, the average balance increases from $\$ 203$ to $\$ 370$, while the fraction of accounts with positive inflows decreases from $99.8 \%$ to $4.4 \%$. The likelihood of any outflow averages around $1.7 \%$. The fact that the likelihood of inflows does not fall to zero suggests either that some employees return to work before their employee status is updated by their employer, or that some individuals contribute directly to their OregonSaves IRA despite not being currently employed by an OregonSaves-participating firm. To the extent that employees accumulate \$370 in an OregonSaves Roth IRA and make no subsequent contributions or withdrawals, they may be unaware that they are participating in the program. ${ }^{30}$

While we find that younger employees are less likely to opt out and more likely to have a positive balance within three months of their initial eligibility date, our earlier analysis does not shed light on the rate at which assets are accumulated. In Table 12, we track employees in different age groups over time, from month 1 (when they make their first contribution into OregonSaves), to month 18. The left panel reports the fraction of participants within each age range classified as active in month $t$. The right panel reports the corresponding average account balances (including

\footnotetext{
${ }^{30}$ In Table Online Appendix 7, we report the 10th, 25th, 50th, 75th, and 90th percentiles of account balances for active and inactive employees, for months 1 through 18.
} 
zeroes), and we see that the likelihood of job turnover is decreasing with age. Only $50.7 \%$ of employees under the age of 26 are still active in month 18, versus $85.7 \%$ of those over the age of 75. As a result, at the end of 18 months, the youngest employees have accumulated an average of \$487, while the oldest employees have accumulated an average of \$887. The highest average account balance is $\$ 1,186$ for those between the ages of 56 and 65 . In other words, while younger employees are more likely to participate, their ability to accumulate assets is hampered by high levels of job turnover. It is also apparent in Table 12 that, while older participants may be less likely to participate, those who do participate accumulate assets at a higher rate than younger participants.

We conclude this section by predicting individual-level monthly inflows and outflows. The dependent variable in column (1) of Table 13 equals 100 if there is an inflow into the account in month t, and zero otherwise. Similarly, the dependent variable in column (2) equals 100 if there is any outflow from the account in month $t$, and zero otherwise. Since outflows are much lumpier than inflows, the likelihood of any inflow is 55.5\%, while the likelihood of any outflow is only 2.6\%. To help quantify the impact of turnover and opt out on inflows and outflows, we include dummy variables to capture whether employees are listed as being actively employed in month $t$, whether they terminate during month $t$, whether they terminate during month $t-1$, and whether the saving rate equals $0 \%$ in month $t$ (which reflect either a formal opt out or a direct change to the saving rate). We include age category fixed effects (reference category is age 18-25); the number of months since the initial contribution fixed effects; calendar year-month fixed effects; and industry fixed effects. Standard errors are clustered by employer.

Table 13 here

As expected, employment status is a significant predictor of inflows. Being classified as 
active increases the likelihood of any inflow by $52.1 \%$ (which is close to the unconditional average of $55.5 \%)$. For those who terminate during month $t$, the coefficient is $24.3 \%$, likely reflecting inflows during the month prior to the job turnover. Predictably, setting the saving rate to $0 \%$ is also associated with a reduced probability of any inflows. Controlling for employment status, we find that the likelihood of any inflow is decreasing in months since the initial contribution, falling by $25.9 \%$ in month 18 . The most striking pattern with respect to the calendar year-month fixed effects is the decline of $13.9 \%$ in April 2020. It is conceivable that this reflects a significant loss of earnings due to COVID-19, one not yet captured by the employment status variable. Finally, while many of the coefficients on the industry fixed effects are large and negative (relative to the reference category of a missing industry code), only those for Arts/Entertainment and Business Support are statistically significant at the 10-percent level or below.

The linear probability model does a much poorer job predicting outflows. While the Rsquared in column (1) is 0.372 , it is only 0.016 in column (2). The main predictors of outflows are recent job turnover, which may reflect the use of outflows to smooth consumption, and decision to set the saving rate to $0 \%$. Younger participants are also slightly more likely to withdraw contributions than older participants.

\section{Conclusion}

We analyze participation decisions and the evolution of account balances in OregonSaves, the first state-sponsored auto IRA in the United States. We find that the program is serving employees across a range of industries, but primarily those with low wages and high turnover. The average participating employee in our sample earns \$2,365 per month, has a within-person standard deviation of monthly earnings of $\$ 945$, and an annual job turnover rate of $38.2 \%$. Consistent with these job traits, OregonSaves participation rates under automatic enrollment are 
significantly lower than in other settings. However, when assessing participation rates between $34.3 \%$ and $62.4 \%$, it is important to recall that OregonSaves targets workers lacking access to a traditional employer-sponsored retirement plan. Only $11 \%$ of the employees targeted by OregonSaves claim to already have retirement savings (half the 22\% level in the nationallyrepresentative SIPP). For everyone else, the counterfactual retirement saving rate is near $0 \%$.

In part, the lower participant rates are consistent with the "can’t afford to save” hypothesis. Opt out rates rise with the local unemployment rate and the volatility of industry income, and employees in industries with lower earnings are more likely to cite that they cannot afford to save when opting out. In a sense, these opt out choices are reassuring because they are likely to reflect an optimal decision to prioritize current consumption (for which the marginal utility is high) over savings. Relatedly, we observe withdrawals following job turnover, which is more common among younger workers, and, during April 2020, we observe a large drop in contributions that we attribute to COVID-19 related job losses and economic uncertainty.

Nonetheless, OregonSaves is generating savings for a substantial number of participants. Over 67,700 participants accumulated more than $\$ 51$ million dollars through April 2020, resulting in an average account balance of $\$ 754$. Consistent with a search costs rationale for the program, we see much higher participation rates among younger workers (who are likely less financially literate) and those being exposed to the OregonSaves program for the second or third time. Because we find very little variation in saving rates, dispersion in account balances is driven by variation in salaries and job tenure. Finally, we also find evidence of the “don't need to save” hypothesis, in that older workers and workers in industries with higher income levels perceive less benefit to participating in OregonSaves.

Overall, we conclude that OregonSaves has meaningfully increased employee savings by 
eliminating search costs. Nevertheless, we have also identified limits to what automatic-enrollment savings plans can achieve when expanded to workers in industries and firms with low wages, volatile wages, and high turnover rates. Specifically, there is reason to believe that at least part of the liquid savings generated by employee contributions were drawn down to smooth consumption during the pandemic. This is not to undermine the value of the saving program; rather it highlights the key role that OregonSaves accounts are playing for lower-paid workers in times of earnings and employment volatility. Less clear is whether these accounts will eventually grow into important vehicles for retirement saving. 


\section{References}

Bee, C. Adam, and Joshua Mitchell. 2017. "Do Older Americans Have More Income Than We Think?” SESHD Working Paper 39.

Belbase, Anek and Geoffrey Sanzenbacker. 2018. “How Have Workers Responded to Oregon’s Auto-IRA?” BCRRC Issue Brief 18-22.

Bernheim, B. Douglas, Andrey Fradkin, and Igor Popov. 2015. "The Welfare Economics of Default Options in 401(k) Plans.” American Economic Review 105(9): 2798-2837.

Beshears, John, James J. Choi, David Laibson, Brigitte C. Madrian, and William L. Skimmyhorn. 2019. "Borrowing to Save? The Impact of Automatic Enrollment on Debt." NBER Working Paper 25876.

Biggs, Andrew G. 2015. “Good News: Retirement Income Still Being Undercounted.” Forbes. https://www.forbes.com/sites/andrewbiggs/2015/07/09/good-news-retirement-incomestill-being-undercounted/\#620a7a26397f

Biggs, Andrew. 2019a. "How Hard Should We Push the Poor to Save for Retirement?" The Journal of Retirement. http://www.aei.org/publication/how-hard-should-we-push-thepoor-to-save-for-retirement-2/

Biggs, Andrew. 2019b. “The 'Retirement Coverage Gap’ is Vastly Exaggerated.” Forbes.com. https://www.forbes.com/sites/andrewbiggs/2019/04/01/new-jersey-secure-choiceretirement-plans-fill-a-coverage-gap-thats-vastly-exaggerated/\#478b535e1fe9

Biggs, A. G. 2016. "What’s Happening with Retirement Saving and Retirement Incomes? Better Data Tell a Better Story.” American Enterprise Institute Report (September 8): https://www.aei.org/research-products/report/whats-happening-with-retirement-savingand-retirement-incomes-better-data-tell-a-better-story/.

Biggs, Andrew, and Sylvester Schieber. 2015. "Why Americans Don’t Face a Retirement Crisis.” AEI Perspectives, March. http://www.aei.org/publication/why-americans-dont-face-aretirement-crisis/.

Board of Governors of the Federal Reserve System. 2019. Report on the Economic Well-Being of U.S. Households in 2018.” May. https://www.federalreserve.gov/publications/files/2018report-economic-well-being-us-households-201905.pdf.

Bradford, Hazel. 2017. “It’s Live: Oregon Launches Plan for Private Sector.” P\&I.com. July 10. http://www.pionline.com/article/20170710/PRINT/170719988/its-live-oregon-launchesplan-for-private-sector?newsletter=plansponsordigest\&issue $=20170710$ \#utm_medium $=$ email\&utm_source $=$ newsletters\&utm_ca mpaign=pi-plan-sponsor-digest-20170712\#cci_r=36658 
Bronchetti, Erin Todd, Thomas S. Dee, David B. Huffman, and Ellen Magenheim. 2013. "When a Nudge Isn’t Enough: Defaults and Saving among Low-Income Tax Filers.” National Tax Journal 66(3): 609-34.

Carlin, Bruce, Simon Gervais, and Gustavo Manso. 2013. "Libertarian Paternalism, Information Production, and Financial Decision Making," Review of Financial Studies 26(9): 22042228.

Carroll, Gabriel D., James J. Choi, David Laibson, Brigitte C. Madrian, and Andrew Metrick. 2009. “Optimal Defaults and Active Decisions.” Quarterly Journal of Economics 124(4): 1639-1674.

Célerier, Claire and Adrien Matray. 2019. "Bank-branch Supply, Financial Inclusion, and Wealth Accumulation.” Review of Financial Studies 32(12): 4767-4809.

Center for Retirement Research (CRR). 2020. Facts About Oregon Saves. November https://crr.bc.edu/wp-content/uploads/2020/12/Oregon_December-2020.pdf

Chalmers, John and Reuter, Jonathan. 2020. "Is Conflicted Advice Better than No Advice?” Journal of Financial Economics 138 (2): 366-387.

Chetty, Raj, John N. Friedman, Søren Leth-Petersen, Torben Heien Nielsen, and Tore Olsen. 2014. "Active vs. Passive Decisions and Crowd-out in Retirement Savings Accounts: Evidence from Denmark.” Quarterly Journal of Economics 129(3): 1141-1219.

Clark, Robert L., Annamaria Lusardi, and Olivia S. Mitchell. (2017). "Financial Literacy and Retirement Plan Behavior: A Case Study.” Economic Inquiry 55(1): 248-259.

Congressional Budget Office (CBO). 2019. "Social Security Replacement Rates and Other Benefit Measures: An In-Depth Analysis.” April. https://www.cbo.gov/system/files/201904/55038-SSReplacementRates.pdf

Cribb, Jonathan, and Carl Emerson. 2019. "Requiring Auto-Enrollment: Lessons from UK Retirement Plans.” CRR Issue Brief 19-6.

Gale, William, and David John. 2018. "State Sponsored Retirement Savings Plans: New Approaches to Boost Retirement Plan Coverage.” In O.S. Mitchell, R. Clark, and R. Maurer, Eds. How Persistent Low Returns Will Shape Saving and Retirement. Oxford: Oxford University Press: 173-193.

Gustman, Alan L. and Thomas L. Steinmeier. 2005. "Imperfect Knowledge of Social Security and Pensions.” Industrial Relations 44(2): 373-398.

Hannagan, Anthony and Morduch, Jonathan. 2015. "Income Gains and Month-to-Month Income Volatility: Household Evidence from the US Financial Diaries.” NYU Wagner Research Paper No. 2659883, US Financial Diaries Working Paper, 2015: 
http://dx.doi.org/10.2139/ssrn.2659883

Ivanov, Asen. 2018. “Optimal Default Policies in Defined Contribution Pension Plans when Employees are Biased." University of London School of Economics and Finance. Working Paper No. 858.

Lusardi, Annamaria and Olivia S. Mitchell. 2007. "Baby Boomer Retirement Security: The Roles of Planning, Financial Literacy, and Housing Wealth.” Journal of Monetary Economics. 54(1): 205-224.

Madrian, Brigitte C., and Dennis F. Shea. 2001. "The Power of Suggestion: Inertia in 401(k) Participation and Savings Behavior.” Quarterly Journal of Economics 116(4): 1149-1187.

Miller, Keith, David Madland, and Christian E. Weller. 2015. "The Reality of the Retirement Crisis.” Center for American Progress Working Paper. https://cdn.americanprogress.org/wp-content/uploads/2015/01/RetirementCrisis1.pdf.

Mitchell, Olivia S. and Stephen P. Utkus. 2012. "Target-Date Funds and Portfolio Selection in 401(k) Plans.” NBER WP 17911.

Morrissey, Monique. 2016. “The State of American Retirement.” Economic Policy Institute. https://www.epi.org/publication/retirement-in-america/

OregonSaves. 2019. “How Much Can I Contribute to my OregonSaves Account?" https://saver.oregonsaves.com/home/savers/contributions.html

Quinby, Laura D., Alicia H. Munnell, Wenliang Hou, Anek Belbase, and Geoffrey T. Sanzenbacher. 2020. "Participation and Pre-Retirement Withdrawals in Oregon's AutoIRA.” Journal of Retirement Summer 2020: 1-14.

Segal Consulting. 2017. State Retirement Initiatives Do More Than Enhance Retirement Security for Private Sector Workers. Winter. https://www.segalco.com/media/2966/data-12017.pdf.

Scott, John and Mark Hines. 2020. "Employers Express Satisfaction with New Oregon Retirement Saving Program.” Pew Charitable Trust Report (July 30). https://www.pewtrusts.org/en/research-and-analysis/articles/2020/07/30/employersexpress-satisfaction-with-new-oregon-retirement-savings-program

Stock, James, and David Wise. 1990. "Pensions, the Option Value of Work, and Retirement." Econometrica 58(5): 1151-1180.

Vanguard. 2019. How America Saves. Valley Forge: The Vanguard Group. https://institutional.vanguard.com/VGApp/iip/site/institutional/researchcommentary/articl e/HowAmericaSaves2019 
Figure 1. Growth in OregonSaves, August 2018 through April 2020

Panel A reports total assets under management in OregonSaves at the end of each month, in millions of dollars. Panel B reports equal-weighted average (non-zero) account balances, inflows, and outflows. Source: Authors calculations; see text.

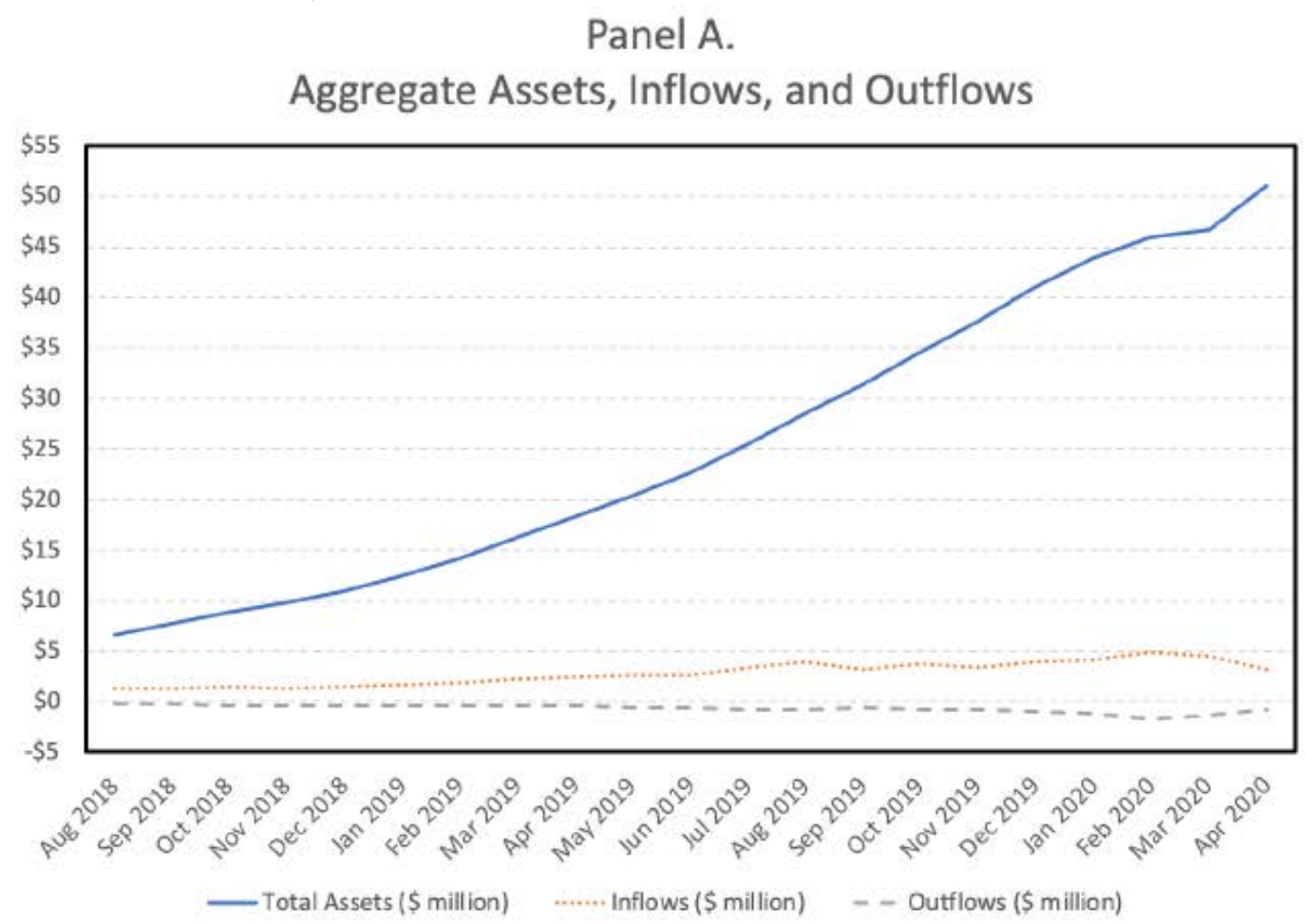

Panel B.

Average Account-level Balance, Inflow, and Outflow

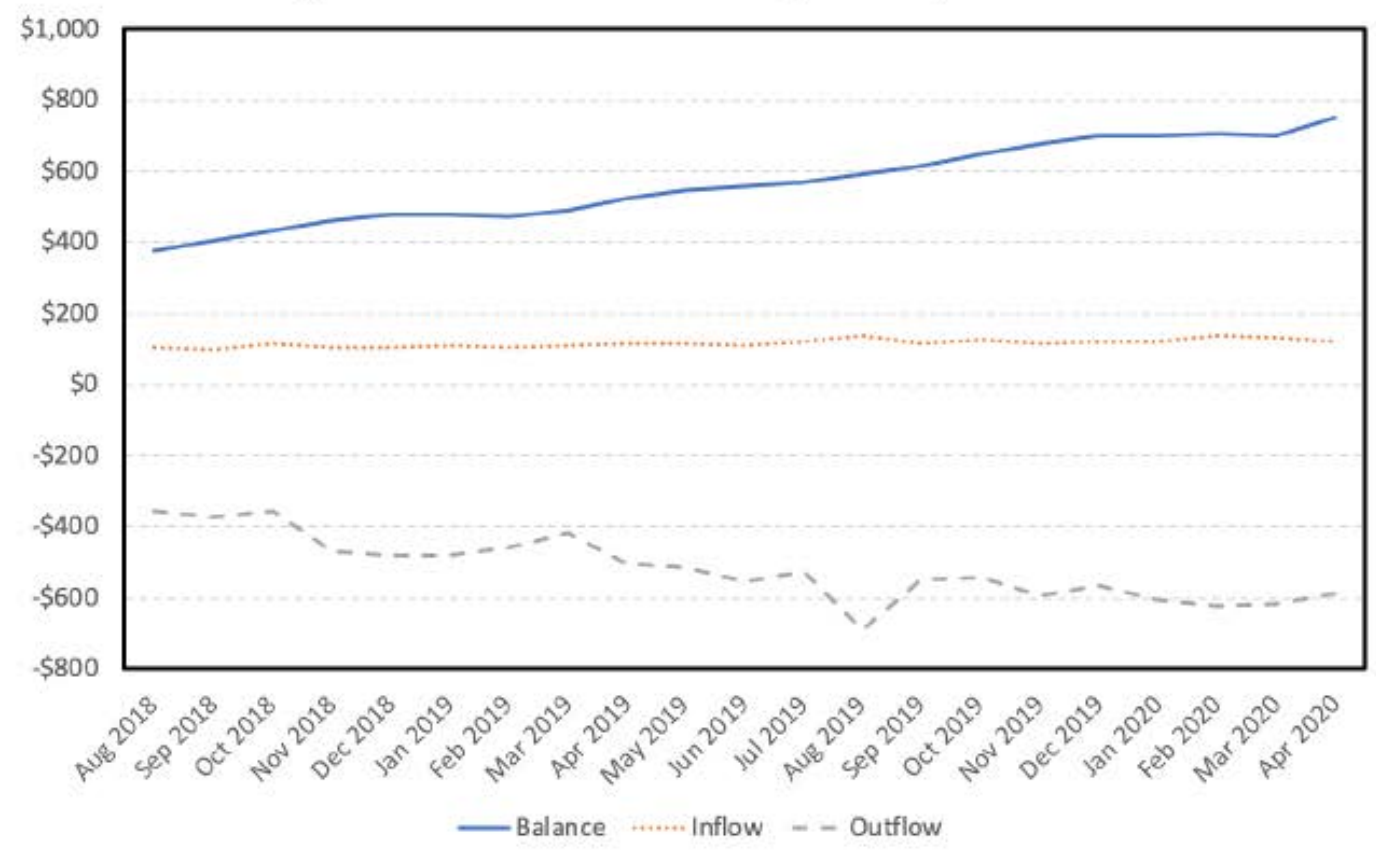




\section{Figure 2. Reductions in the Likelihood of Contributions over Time}

Panel A focuses on workers who have made at least one contribution into OregonSaves during our sample period and reports the fraction making at least $X$ contributions over 3, 6, 12, and 18 month periods. Panel $\mathrm{B}$ focuses on the 18-month sample and reports the fraction of workers who are classified as inactive in the months following the initial contribution, set their saving rate to $0 \%$, or both. Source: Authors calculations; see text.

\section{Panel A. Fraction of OregonSaves Contributors Making}

At Least $X$ Contributions over Different Horizons

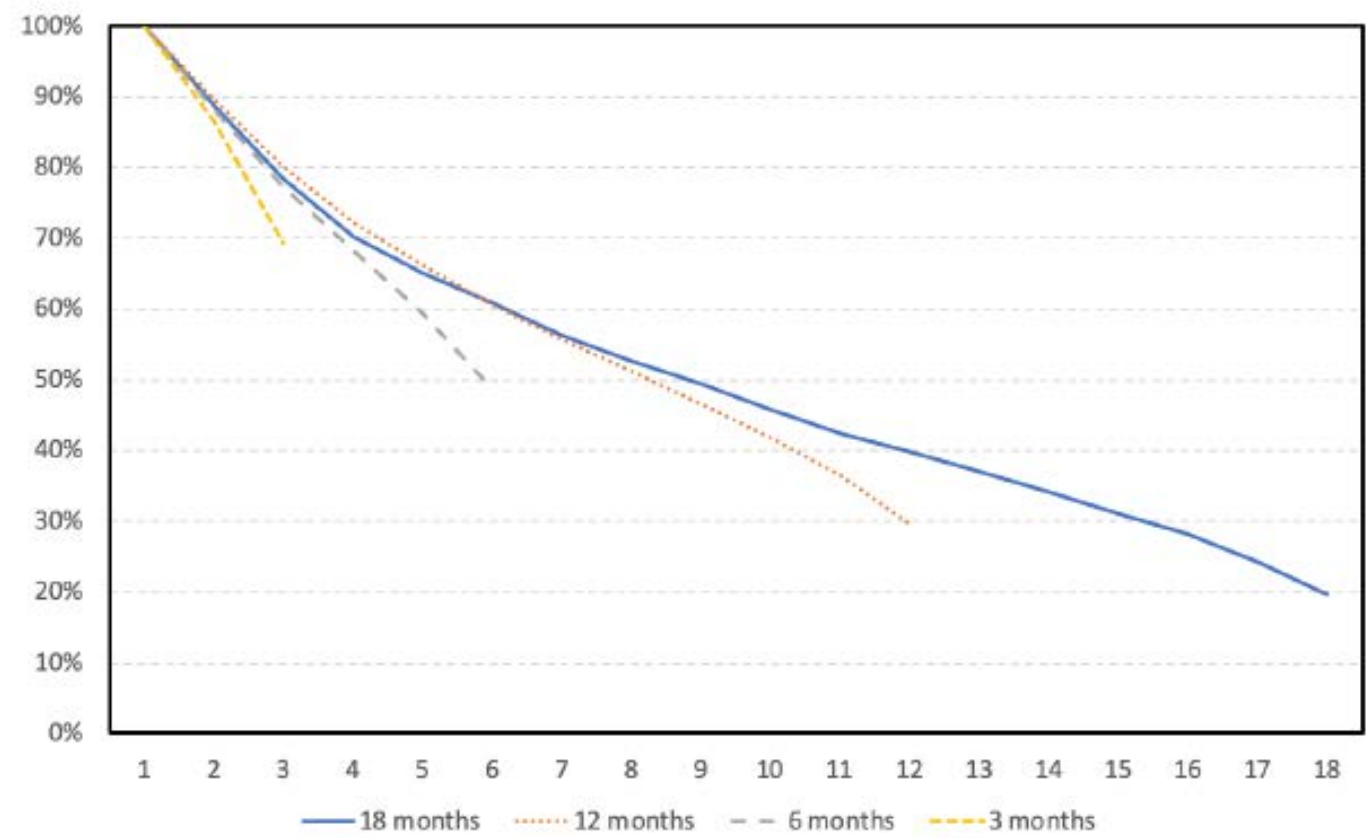

Panel B. Changes in Employee Status and Saving Rate over 18 Months since Initial OregonSaves Contribution

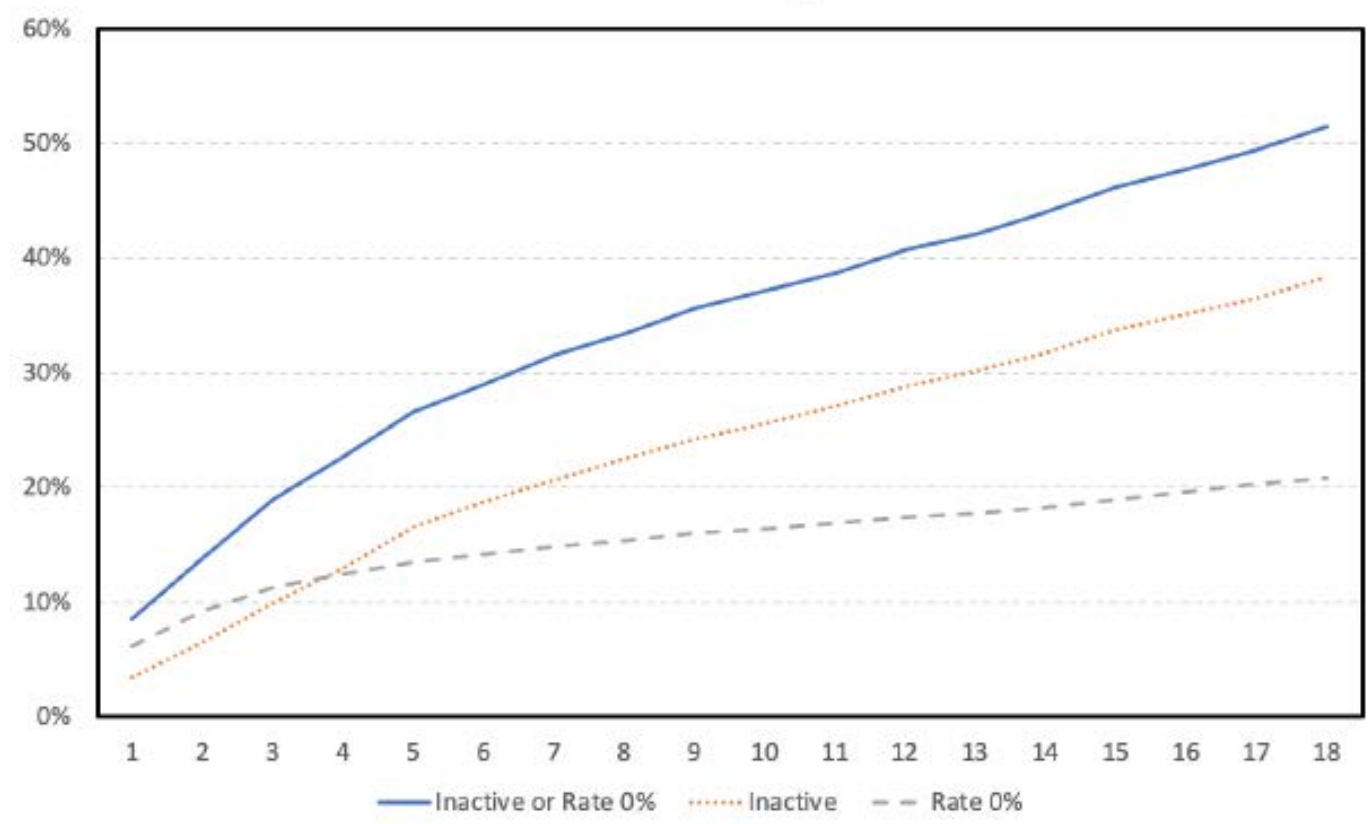


Table 1: Growth of OregonSaves, August 2018 - April 2020

In this table, we summarize the growth of OregonSaves. The unit of observation in columns (1) and (2) is the employer. We report the total number of employers that have uploaded employees' information to the OregonSaves administrator during or before month $t$, and the subset of employers that have processed contributions for at least one employee. The unit of observation in the remaining columns is the employer-employee pair. Column (3) reports the total number of employees uploaded to the administrator and column (4) reports the subset working at employers that have processed contributions. Column (5) reports the number of employees who are classified by the administrator as both eligible to participate and actively working, and column (6) reports the subset working at employers that have processed contributions. Column (7) reports the number of employees in column (3) with positive account balances in month $t$ and column (8) reports the number that ever have a positive account balance. Because employee identifiers are unique to employee-employer pairs, and because some individual work for multiple employers over our sample period, the number of employees with accounts overstates the number of accounts. Finally, we report two participation rates. The global participation rate is defined as the number of employees with current positive account balances (column (7)) divided by the total number of employees (column (4)). The feasible participation rate is defined as the number of employees who ever have a positive account balance (column (8)) divided by the number of number of active, eligible employees working at employers that have already processed payroll (column (6)). Source: Authors calculations.

\begin{tabular}{|c|c|c|c|c|c|c|c|c|c|c|}
\hline \multirow[b]{4}{*}{ Date } & \multicolumn{2}{|c|}{ Employers } & \multicolumn{4}{|c|}{ Employee-Employer Pairs } & \multicolumn{2}{|c|}{ Positive Balance? } & \multicolumn{2}{|c|}{ Participation Rate } \\
\hline & & & & Employer & & Eligible & & & & \\
\hline & & Processed & & Processed & Eligible & \& Active & & & & \\
\hline & $\begin{array}{r}\text { Total } \\
\text { (1) }\end{array}$ & $\begin{array}{r}\text { Contributions } \\
\text { (2) }\end{array}$ & $\begin{array}{r}\text { Total } \\
\text { (3) }\end{array}$ & $\begin{array}{r}\text { Contributions } \\
\text { (4) }\end{array}$ & $\begin{array}{r}\text { \& Active } \\
\text { (5) }\end{array}$ & $\begin{array}{r}\& \text { Contributions } \\
\text { (6) }\end{array}$ & $\begin{array}{r}\text { Currently } \\
\text { (7) }\end{array}$ & $\begin{array}{r}\text { Ever } \\
(8)\end{array}$ & $\begin{array}{r}\text { Global } \\
(9)=(7) /(4)\end{array}$ & $\begin{array}{r}\text { Feasible } \\
(10)=(8) /(6)\end{array}$ \\
\hline Aug 2018 & 846 & 524 & 72,092 & 60,102 & 48,305 & 40,638 & 18,703 & 24,145 & $31.1 \%$ & $59.4 \%$ \\
\hline Sep 2018 & 902 & 569 & 76,460 & 64,720 & 51,776 & 44,324 & 20,177 & 25,569 & $31.2 \%$ & $57.7 \%$ \\
\hline Oct 2018 & 1,001 & 620 & 82,081 & 69,344 & 54,345 & 46,604 & 21,415 & 27,589 & $30.9 \%$ & $59.2 \%$ \\
\hline Nov 2018 & 1,184 & 666 & 89,834 & 73,602 & 58,232 & 49,464 & 22,727 & 30,171 & $30.9 \%$ & $61.0 \%$ \\
\hline Dec 2018 & 1,740 & 745 & 107,127 & 78,651 & 63,860 & 52,804 & 24,430 & 36,166 & $31.1 \%$ & $68.5 \%$ \\
\hline Jan 2019 & 2,162 & 1,039 & 122,319 & 90,620 & 77,631 & 60,227 & 27,943 & 41,126 & $30.8 \%$ & $68.3 \%$ \\
\hline Feb 2019 & 2,368 & 1,324 & 128,931 & 102,025 & 89,851 & 70,027 & 31,980 & 43,347 & $31.3 \%$ & $61.9 \%$ \\
\hline Mar 2019 & 2,600 & 1,540 & 137,145 & 110,369 & 94,704 & 76,036 & 35,505 & 45,809 & $32.2 \%$ & $60.2 \%$ \\
\hline Apr 2019 & 3,029 & 1,677 & 147,725 & 117,698 & 100,109 & 79,964 & 38,062 & 49,255 & $32.3 \%$ & $61.6 \%$ \\
\hline May 2019 & 4,288 & 1,862 & 170,180 & 125,689 & 108,515 & 84,830 & 40,622 & 55,530 & $32.3 \%$ & $65.5 \%$ \\
\hline Jun 2019 & 4,990 & 2,299 & 186,888 & 139,582 & 127,981 & 94,068 & 45,062 & 60,256 & $32.3 \%$ & $64.1 \%$ \\
\hline Jul 2019 & 5,403 & 2,807 & 197,200 & 152,396 & 139,720 & 103,895 & 49,661 & 63,540 & $32.6 \%$ & $61.2 \%$ \\
\hline Aug 2019 & 5,897 & 3,130 & 207,220 & 163,124 & 145,804 & 110,573 & 53,556 & 66,367 & $32.8 \%$ & $60.0 \%$ \\
\hline Sep 2019 & 6,261 & 3,370 & 216,282 & 171,154 & 149,848 & 113,018 & 56,705 & 69,203 & $33.1 \%$ & $61.2 \%$ \\
\hline Oct 2019 & 7,102 & 3,568 & 227,563 & 178,174 & 154,160 & 115,798 & 59,677 & 72,735 & $33.5 \%$ & $62.8 \%$ \\
\hline Nov 2019 & 9,097 & 3,842 & 245,976 & 185,165 & 161,525 & 119,638 & 62,616 & 77,341 & $33.8 \%$ & $64.6 \%$ \\
\hline Dec 2019 & 10,118 & 4,380 & 262,518 & 194,649 & 174,406 & 124,138 & 66,594 & 81,392 & $34.2 \%$ & $65.6 \%$ \\
\hline Jan 2020 & 10,541 & 4,988 & 272,990 & 208,826 & 183,977 & 130,239 & 71,021 & 83,979 & $34.0 \%$ & $64.5 \%$ \\
\hline Feb 2020 & 10,799 & 5,285 & 280,075 & 217,289 & 190,313 & 136,149 & 74,218 & 85,505 & $34.2 \%$ & $62.8 \%$ \\
\hline Mar 2020 & 10,978 & 5,444 & 286,121 & 222,527 & 192,841 & 138,126 & 76,344 & 86,179 & $34.3 \%$ & $62.4 \%$ \\
\hline Apr 2020 & 11,088 & 5,537 & 289,657 & 226,178 & 193,993 & 138,465 & 77,652 & 86,380 & $34.3 \%$ & $62.4 \%$ \\
\hline
\end{tabular}




\section{Table 2: OregonSaves Employees by Industry}

In this table, we provide employee-level summary statistics by industry and within the full sample of employees. "All" corresponds to column (6) of Table 1; "Eligible \& Active \& Contributions" corresponds to column (6). Statistics are reported for the "All" sample. Age is defined as the calendar year in which the employee first appears in the administrative data minus the stated year of birth. We report the mean, median, and interquartile range. We report two measures of turnover. Annual turnover equals one if the employee was classified as "terminated," "seasonal layoff," or "out of business" twelve months after becoming eligible to contribute (one observation per employee with at least twelve months of administrative data). Similarly, monthly turnover equals one if the employee was "active" in month $t$-1 but "terminated," "seasonal layoff," or "out of business" in month $t$ (unit of observations is employee-month). Monthly after-tax earnings are estimated at the employee-month level as total monthly contributions divided by current savings rate (e.g., $\$ 100 / 5 \%=\$ 2,000$ ). Monthly earnings can only be estimated for the subset of contributors. We report the mean, median, and interquartile range. Finally, we report the within-employee standard deviation of monthly earnings, calculated at the employee level using all months with positive contributions within each employee-employer pair. Source: Authors calculations.

\begin{tabular}{|c|c|c|c|c|c|c|c|c|c|c|c|}
\hline & \multicolumn{2}{|c|}{ Employees } & \multicolumn{3}{|c|}{ Age } & \multicolumn{2}{|c|}{ Turnover } & \multicolumn{4}{|c|}{ Monthly Earnings } \\
\hline \multirow[b]{3}{*}{ Industry } & & Eligible & & & & & & & & & Within \\
\hline & & \& Active & & & & & & & & & Employee \\
\hline & $\begin{array}{l}\text { All } \\
\text { (1) }\end{array}$ & $\begin{array}{r}\& \text { Contributions } \\
\text { (2) }\end{array}$ & $\begin{array}{r}\text { Mean } \\
(3)\end{array}$ & $\begin{array}{r}\text { Median } \\
\text { (4) }\end{array}$ & $\begin{array}{r}\text { IQR } \\
(5)\end{array}$ & $\begin{array}{r}\text { Annual } \\
(6)\end{array}$ & $\begin{array}{r}\text { Monthly } \\
\text { (7) }\end{array}$ & $\begin{array}{r}\text { Mean } \\
(8)\end{array}$ & $\begin{array}{r}\text { Median } \\
\text { (9) }\end{array}$ & $\begin{array}{l}\text { IQR } \\
(10)\end{array}$ & $\begin{array}{r}\text { Std Dev } \\
\text { (11) }\end{array}$ \\
\hline Missing & 12,795 & 6,179 & 33.8 & 30 & 17 & $41.8 \%$ & $3.8 \%$ & 2,445 & 1,940 & 1,860 & 936 \\
\hline Agriculture & 21,593 & 9,144 & 38.9 & 37 & 22 & $25.7 \%$ & $1.7 \%$ & 3,130 & 2,680 & 2,280 & 1,360 \\
\hline Arts/Entertainment & 8,770 & 5,036 & 35.1 & 31 & 20 & $30.6 \%$ & $2.1 \%$ & 1,638 & 1,100 & 1,860 & 685 \\
\hline Business Support & 32,930 & 18,184 & 36.8 & 34 & 22 & $31.5 \%$ & $2.3 \%$ & 2,047 & 1,700 & 1,807 & 844 \\
\hline Construction & 13,344 & 6,067 & 39.2 & 38 & 20 & $19.9 \%$ & $1.5 \%$ & 4,040 & 3,540 & 2,620 & 1,661 \\
\hline Education & 4,704 & 2,910 & 39.0 & 37 & 22 & $32.4 \%$ & $2.3 \%$ & 1,983 & 1,380 & 2,220 & 888 \\
\hline Finance and Insurance & 417 & 108 & 45.8 & 45 & 25 & $0.0 \%$ & $0.6 \%$ & 4,165 & 2,900 & 1,440 & 1,446 \\
\hline Food Services & 91,342 & 42,359 & 32.1 & 29 & 17 & $43.9 \%$ & $3.4 \%$ & 1,985 & 1,617 & 1,560 & 800 \\
\hline Health Care & 26,893 & 13,047 & 37.9 & 34 & 24 & $46.6 \%$ & $3.2 \%$ & 2,242 & 1,860 & 1,740 & 885 \\
\hline Information & 1,249 & 737 & 38.4 & 36 & 22 & $34.9 \%$ & $2.2 \%$ & 3,276 & 2,720 & 2,940 & 1,331 \\
\hline Management & 576 & 242 & 30.9 & 26 & 16 & $73.6 \%$ & $4.4 \%$ & 2,897 & 2,120 & 2,660 & 1,114 \\
\hline Manufacturing & 16,510 & 8,219 & 39.2 & 37 & 21 & $36.9 \%$ & $2.8 \%$ & 3,053 & 2,580 & 2,067 & 1,265 \\
\hline Mining/Oil/Gas & 144 & 25 & 47.9 & 52 & 28 & & $1.7 \%$ & 3,721 & 3,900 & 1,520 & 822 \\
\hline Other Services & 12,375 & 5,544 & 39.1 & 35 & 23 & $39.4 \%$ & $2.5 \%$ & 2,472 & 2,057 & 2,000 & 974 \\
\hline Professional/Scientific & 5,376 & 2,846 & 39.4 & 37 & 22 & $35.5 \%$ & $2.2 \%$ & 3,844 & 2,920 & 3,180 & 1,698 \\
\hline Real Estate & 4,255 & 2,178 & 42.8 & 41 & 24 & $22.7 \%$ & $1.9 \%$ & 3,379 & 2,833 & 2,480 & 1,431 \\
\hline Retail Trade & 25,509 & 11,425 & 37.4 & 34 & 24 & $39.7 \%$ & $2.8 \%$ & 2,381 & 1,883 & 1,760 & 946 \\
\hline Transportation/Storage & 6,472 & 2,258 & 41.6 & 40 & 26 & $21.8 \%$ & $1.7 \%$ & 3,011 & 2,640 & 2,180 & 1,178 \\
\hline Wholesale Trade & 4,403 & 1,957 & 41.0 & 39 & 22 & $40.6 \%$ & $2.5 \%$ & 3,892 & 3,200 & 2,460 & 1,537 \\
\hline All & 289,657 & 138,465 & 36.2 & 33 & 22 & $38.2 \%$ & $2.7 \%$ & 2,365 & 1,883 & 1,960 & 945 \\
\hline
\end{tabular}




\section{Table 3: OregonSaves Opt-Out Rates and Initial Account Balances by Industry}

In this table, the unit of observation is employee $i$ three months after the date on which the employee would be eligible to contribute to OregonSaves (where the eligibility date is set under the assumptions that her identify is verified and she remains employed). We report the number of employees in column (1). The focus on each employee during this particular month explains the reduced sample size relative to Tables 1 and 2. Column (2) reports the fraction of these employees who have formally opted out of OregonSaves within three months of eligibility. Columns (3) and (4) condition the sample on having opted out and report the fraction that list the reason for opting out as "I can't afford to save at this time" or "I have my own retirement plan," respectively. Columns (5), (6), and (7) report the fractions of all employees without an account (which includes the vast majority of employees who opt out), with an account balance of $\$ 0$, or with a positive account balance. The remaining columns focus on the subset of employees with positive account balances after three months of eligibility and report the mean, median, and interquartile range of their account balance three months after being eligible. Source: Authors calculations.

\begin{tabular}{|c|c|c|c|c|c|c|c|c|c|c|c|c|c|}
\hline \multirow[b]{2}{*}{ Industry } & \multirow[b]{2}{*}{$\begin{array}{r}\text { Employees } \\
\text { (1) }\end{array}$} & \multirow[b]{2}{*}{$\begin{array}{r}\text { Formal } \\
\text { opt out } \\
(2)\end{array}$} & \multicolumn{2}{|c|}{ Conditional on Opt Out } & \multicolumn{3}{|c|}{ Account status } & \multicolumn{6}{|c|}{ Conditional on Account $>\$ 0$} \\
\hline & & & $\begin{array}{r}\text { Cannot } \\
\text { afford } \\
\text { (3) }\end{array}$ & $\begin{array}{r}\text { Existing } \\
\text { plan } \\
(4)\end{array}$ & $\begin{array}{r}\text { None } \\
(5)\end{array}$ & $\begin{array}{l}\$ 0 \\
(6)\end{array}$ & $\begin{array}{r}>\$ 0 \\
(7)\end{array}$ & & $\begin{array}{r}\text { Mean } \\
(8)\end{array}$ & & $\begin{array}{r}\text { Median } \\
(9)\end{array}$ & & $\begin{array}{l}\text { IQR } \\
(10)\end{array}$ \\
\hline Missing & 7,146 & $29.4 \%$ & $34.7 \%$ & $25.3 \%$ & $62.4 \%$ & $2.4 \%$ & $35.2 \%$ & $\$$ & 365 & $\$$ & 194 & $\$$ & 268 \\
\hline Agriculture & 16,936 & $47.7 \%$ & $23.5 \%$ & $14.7 \%$ & $89.7 \%$ & $0.5 \%$ & $9.8 \%$ & $\$$ & 357 & $\$$ & 306 & $\$$ & 365 \\
\hline Arts/Entertainment & 7,189 & $39.3 \%$ & $23.6 \%$ & $40.1 \%$ & $69.2 \%$ & $0.9 \%$ & $29.9 \%$ & $\$$ & 192 & $\$$ & 111 & $\$$ & 197 \\
\hline Business Support & 22,338 & $36.3 \%$ & $34.4 \%$ & $19.5 \%$ & $75.0 \%$ & $1.2 \%$ & $23.8 \%$ & $\$$ & 231 & $\$$ & 167 & $\$$ & 277 \\
\hline Construction & 11,407 & $51.4 \%$ & $27.7 \%$ & $28.3 \%$ & $79.7 \%$ & $1.1 \%$ & $19.2 \%$ & $\$$ & 450 & $\$$ & 391 & $\$$ & 429 \\
\hline Education & 4,348 & $47.5 \%$ & $22.5 \%$ & $41.1 \%$ & $68.3 \%$ & $1.0 \%$ & $30.7 \%$ & $\$$ & 230 & $\$$ & 135 & $\$$ & 269 \\
\hline Finance and Insurance & 335 & $74.3 \%$ & $14.5 \%$ & $44.2 \%$ & $90.1 \%$ & $0.0 \%$ & $9.9 \%$ & $\$$ & 437 & $\$$ & 304 & $\$$ & 327 \\
\hline Food Services & 70,486 & $32.2 \%$ & $35.0 \%$ & $21.6 \%$ & $66.3 \%$ & $1.7 \%$ & $32.0 \%$ & $\$$ & 229 & $\$$ & 172 & $\$$ & 216 \\
\hline Health Care & 19,688 & $38.9 \%$ & $35.0 \%$ & $26.8 \%$ & $64.2 \%$ & $1.9 \%$ & $33.9 \%$ & $\$$ & 240 & $\$$ & 183 & $\$$ & 238 \\
\hline Information & 1,100 & $52.5 \%$ & $29.8 \%$ & $32.4 \%$ & $68.5 \%$ & $0.9 \%$ & $30.5 \%$ & $\$$ & 292 & $\$$ & 207 & $\$$ & 370 \\
\hline Management & 325 & $46.2 \%$ & $24.7 \%$ & $28.7 \%$ & $70.2 \%$ & $0.6 \%$ & $29.2 \%$ & $\$$ & 270 & $\$$ & 186 & $\$$ & 275 \\
\hline Manufacturing & 12,786 & $51.1 \%$ & $28.0 \%$ & $28.3 \%$ & $74.2 \%$ & $1.1 \%$ & $24.7 \%$ & $\$$ & 333 & $\$$ & 275 & $\$$ & 331 \\
\hline Mining/Oil/Gas & 118 & $81.4 \%$ & $14.6 \%$ & $43.8 \%$ & $90.7 \%$ & $0.0 \%$ & $9.3 \%$ & $\$$ & 378 & $\$$ & 392 & $\$$ & 647 \\
\hline Other Services & 10,638 & $52.6 \%$ & $26.7 \%$ & $35.4 \%$ & $72.4 \%$ & $1.2 \%$ & $26.4 \%$ & $\$$ & 286 & $\$$ & 222 & $\$$ & 267 \\
\hline Professional/Scientific & 4,791 & $54.4 \%$ & $22.1 \%$ & $36.3 \%$ & $76.5 \%$ & $1.0 \%$ & $22.5 \%$ & $\$$ & 462 & $\$$ & 305 & $\$$ & 434 \\
\hline Real Estate & 3,473 & $57.4 \%$ & $26.6 \%$ & $32.5 \%$ & $75.6 \%$ & $1.4 \%$ & $23.0 \%$ & $\$$ & 383 & $\$$ & 295 & $\$$ & 372 \\
\hline Retail Trade & 20,260 & $47.3 \%$ & $30.4 \%$ & $27.7 \%$ & $73.7 \%$ & $1.5 \%$ & $24.9 \%$ & $\$$ & 254 & $\$$ & 199 & $\$$ & 243 \\
\hline Transportation/Storage & 5,397 & $37.3 \%$ & $29.4 \%$ & $31.4 \%$ & $79.8 \%$ & $1.4 \%$ & $18.8 \%$ & $\$$ & 354 & $\$$ & 313 & $\$$ & 349 \\
\hline Wholesale Trade & 3,346 & $59.4 \%$ & $27.3 \%$ & $29.2 \%$ & $79.9 \%$ & $1.1 \%$ & $19.0 \%$ & $\$$ & 416 & $\$$ & 320 & $\$$ & 345 \\
\hline All & 222,107 & $40.9 \%$ & $30.3 \%$ & $25.9 \%$ & $71.9 \%$ & $1.4 \%$ & $26.7 \%$ & $\$$ & 268 & $\$$ & 192 & $\$$ & 265 \\
\hline
\end{tabular}




\section{Table 4: Reasons for Formally Opting Out of OregonSaves}

In this table, we summarize the reasons that employees give for formally opting out of OregonSaves. Employees who opt out are presented with a list of seven reasons ("I can't afford to save at this time" through "I'm not satisfied with the investment options") and asked to choose one. Employees were also allowed to choose "Other" and fill out an open response. Of the 31,284 employees who choose "Other." 8,836 provide a comment. After classifying the 8,836 comments into narrow categories, we determined that 726 of the comments matched one of the seven prespecified reasons. The most popular of the remaining 8,110 comments are summarized in the lower panel. Differences between columns (3) and (4) of Table 3 and "I can't afford to save" and "I have my own retirement plan" in this table are driven by the smaller sample size in Table 3 (which conditions on three months after the initial eligibility date). Source: Authors calculations.

\begin{tabular}{lrr}
\hline Primary reason for opting out & Count & $\%$ \\
\hline I can't afford to save at this time & 33,507 & $28.6 \%$ \\
I don't qualify for a Roth IRA due to my income & 644 & $0.5 \%$ \\
I don't trust the financial markets & 3,635 & $3.1 \%$ \\
I have my own retirement plan & 28,064 & $23.9 \%$ \\
I would prefer a Traditional IRA & 1,636 & $1.4 \%$ \\
I'm not interested in contributing through this employer & 17,027 & $14.5 \%$ \\
I'm not satisfied with the investment options & 2,274 & $1.9 \%$ \\
Other (no open response) & 22,448 & $19.1 \%$ \\
Other (open response) & 8,110 & $6.9 \%$ \\
All & 117,345 & $100.0 \%$ \\
\hline Most popular open response answers & & $\%$ \\
\hline Not interested & & $2.4 \%$ \\
Age: Near/in retirement & 2,819 & $2.4 \%$ \\
Objects to state-sponsored plan / auto-enrollment & 991 & $0.8 \%$ \\
Eligibility: No longer employed there & 954 & $0.8 \%$ \\
Part time / temporary work & 805 & $0.7 \%$ \\
Eligibility: Leaving / outside Oregon & 477 & $0.4 \%$ \\
Prefers to choose own plan & 378 & $0.3 \%$ \\
Not ready to save / participate & 292 & $0.2 \%$ \\
Advised against plan & 289 & $0.2 \%$ \\
Wants to research plan & 221 & $0.2 \%$ \\
Does not need plan & 151 & $0.1 \%$ \\
Design: Fees are too high & 134 & $0.1 \%$ \\
Design: Lack of employer match & 94 & $0.1 \%$ \\
Technical difficulties & $59 \%$ \\
All other reasons & 45 & $0.3 \%$ \\
\hline
\end{tabular}




\section{Table 5: Predicting Opt Out from OregonSaves}

In this table, we estimate linear probability models to predict opt out from OregonSaves. The unit of observation is employee $i$. The dependent variable equals 100 if employee $i$ has formally opted out of OregonSaves three months after her initial eligibility date, and zero otherwise. Employee-level independent variables include age category dummy variables (omitted category is ages 18-25); account holder location dummy variables (omitted category is account holder lives in an urban Oregon zip code); OregonSaves job number 2 or 3+ dummy variables; and an employee $i$ terminated in or before month $t$ dummy variable. Employer-level variables include firm size (natural logarithm of the number of employees when enrolling) and dummy variables indicating whether the employer joined OregonSaves during the pilot phase, whether the employer registered after the OregonSaves deadline based on firm size, and whether the employer has processed payroll for at least one employee through month $t$. Industry-level variables include median employee income within the industry in month $t$ and standard deviation of employee income within the industry in month $t$. Columns that controls for the average unemployment rate in the account holder's county over the prior three months are limited to employees living in Oregon and Washington. Column (4) includes the fraction of employee i's coworkers that had formally opted out in month $t-1$. All columns include year-month fixed effects. Columns (3) and (4) include industry fixed effects. Standard errors cluster on employer. Statistical significance at the 1-percent, 5-percent, and 10-percent levels is indicated by ***,**, and *, respectively. Source: Authors calculations.

\begin{tabular}{|c|c|c|c|c|c|}
\hline & \multicolumn{5}{|c|}{ Predicting opt out 3 months after eligibility } \\
\hline & (1) & (2) & (3) & (4) & (5) \\
\hline \multirow[t]{2}{*}{ Age $26-35(t)$} & $5.38 * \approx$ & $5.44 * \approx$ & $4.89 * 8$ & $3.86 * 8$ & $3.94 * 8$ \\
\hline & $(0.46)$ & $(0.46)$ & $(0.40)$ & $(0.29)$ & $(0.29)$ \\
\hline \multirow[t]{2}{*}{ Age $36-45(t)$} & $8.24 * \approx$ & $8.34 * \approx$ & $7.60 * \approx$ & $5.23 \approx$ & $5.72 \approx$ \\
\hline & $(0.60)$ & $(0.60)$ & $(0.51)$ & $(0.36)$ & $(0.34)$ \\
\hline \multirow[t]{2}{*}{ Age $46-55(t)$} & $11.32 * *$ & $11.31 * *$ & $10.42 * *$ & $6.45 * *$ & $7.03 * \approx$ \\
\hline & $(0.64)$ & $(0.64)$ & $(0.54)$ & $(0.39)$ & $(0.38)$ \\
\hline \multirow[t]{2}{*}{ Age $56-65(t)$} & $20.59 * \approx$ & $20.54 * *$ & $19.33 * *$ & $13.28 * *$ & $13.69 \approx$ \\
\hline & $(0.80)$ & $(0.79)$ & $(0.66)$ & $(0.48)$ & $(0.47)$ \\
\hline \multirow[t]{2}{*}{ Age $66-75(t)$} & $31.76 * *$ & $31.52 * *$ & $30.15 * *$ & $22.34 * *$ & $23.62 * \approx$ \\
\hline & $(0.93)$ & $(0.96)$ & $(0.83)$ & $(0.66)$ & $(0.68)$ \\
\hline \multirow[t]{2}{*}{ Age $>75(t)$} & $36.23 * *$ & $36.31 * *$ & $34.41 * *$ & $23.63 * * *$ & $25.12 * *$ \\
\hline & $(1.52)$ & $(1.52)$ & $(1.49)$ & (1.31) & $(1.37)$ \\
\hline \multirow[t]{2}{*}{ Account holder in rural Oregon? $(t)$} & 0.12 & $1.76^{* *}$ & 0.09 & -0.37 & -0.23 \\
\hline & $(0.84)$ & $(0.87)$ & $(0.75)$ & $(0.36)$ & $(0.36)$ \\
\hline \multirow[t]{2}{*}{ Account holder live outside Oregon? (t) } & -4.03 & -6.16 & -4.22 & -0.94 & 0.59 \\
\hline & $(2.58)$ & $(3.29)$ & $(2.50)$ & $(0.92)$ & $(0.76)$ \\
\hline \multirow[t]{2}{*}{ OregonSaves job number $2(t)$} & $-6.14 * *$ & $-6.04 * \approx$ & $-5.33 * \approx$ & $-3.54 * * 8$ & $-2.70 * s$ \\
\hline & $(0.56)$ & $(0.57)$ & $(0.54)$ & $(0.40)$ & $(0.38)$ \\
\hline \multirow[t]{2}{*}{ OregonSaves job number $3+(t)$} & $-7.89 \approx * *$ & $-10.28 * \approx$ & $-8.06 * \approx$ & $-6.68 * \approx$ & $-2.12 *$ \\
\hline & $(1.53)$ & $(2.21)$ & (1.89) & $(1.47)$ & $(1.16)$ \\
\hline \multirow[t]{2}{*}{ Employee terminated? $(\mathrm{t})$} & $-16.15 * *$ & $-15.92 \approx$ & $-15.80 * \approx$ & $-15.48 * \approx$ & $-17.62 \approx *$ \\
\hline & $(1.25)$ & $(1.27)$ & $(1.22)$ & $(0.81)$ & $(0.71)$ \\
\hline Average county unemployment & $1.52 * \approx$ & & $1.61 * *$ & 0.17 & -0.03 \\
\hline rate $(\mathrm{t}-3$ to $\mathrm{t}-1)$ & $(0.50)$ & & $(0.50)$ & $(0.23)$ & $(0.31)$ \\
\hline \multirow[t]{2}{*}{ Opt out fraction within ER (t-1) } & & & & $81.81 * *$ & \\
\hline & & & & $(0.94)$ & \\
\hline \multirow[t]{2}{*}{ Ln (number of employees) (t) } & $-4.38 * \approx *$ & $-4.51 * \approx$ & $-4.29 * 8 *$ & $-1.88 * * *$ & \\
\hline & $(1.17)$ & (1.18) & $(1.01)$ & $(0.54)$ & \\
\hline \multirow[t]{2}{*}{ Pilot employer? (t) } & $-14.19 * *$ & $-14.69 * \approx$ & $-15.58 * \approx$ & $-6.94 * \approx$ & \\
\hline & $(2.96)$ & $(3.10)$ & $(3.91)$ & $(1.93)$ & \\
\hline \multirow[t]{2}{*}{ Employer registered late? $(\mathrm{t})$} & -1.75 & -1.40 & -1.52 & 0.60 & \\
\hline & $(1.38)$ & $(1.43)$ & $(1.24)$ & $(0.57)$ & \\
\hline \multirow[t]{2}{*}{ Employer processed payroll? (t) } & $-5.24 * \approx$ & $-4.57 * \approx$ & $-5.08 * 8$ & -1.01 & $4.89 *$ \\
\hline & $(1.65)$ & $(1.76)$ & $(1.52)$ & $(0.68)$ & $(2.67)$ \\
\hline \multirow[t]{2}{*}{ Median industry income $(\mathrm{t})$} & $4.57 \approx \approx$ & $3.70 \approx$ & 3.37 & 2.59 & \\
\hline & (1.19) & (1.28) & $(5.60)$ & $(2.05)$ & \\
\hline \multirow[t]{2}{*}{ SD industry income $(t)$} & $2.24 *$ & $2.80 * *$ & 0.91 & 0.85 & \\
\hline & $(0.88)$ & $(1.00)$ & $(1.02)$ & $(0.70)$ & \\
\hline
\end{tabular}




\begin{tabular}{|c|c|c|c|c|c|}
\hline Limited to accounts in OR or WA? & Yes & -. & Yes & Yes & Yes \\
\hline Year-month FE? & Yes & Yes & Yes & Yes & Yes \\
\hline Industry FE? & -. & -. & Yes & Yes & -. \\
\hline Employer FE? & - & -. & - & - & Yes \\
\hline $\mathrm{N}$ & 215,835 & 220,355 & 215,835 & 207,977 & 217,575 \\
\hline Adj. R2 & 0.0987 & 0.0986 & 0.1040 & 0.2748 & 0.3100 \\
\hline Mean Dependent: & 41.26 & 40.92 & 41.26 & 41.23 & 41.23 \\
\hline
\end{tabular}




\section{Table 6: Predicting Positive Account Balances}

In this table, we estimate linear probability models to predict positive OregonSaves account balances conditional on not having formally opted out. The unit of observation is employee $i$. The dependent variable equals 100 if employee $i$ has a positive account balance three months after her initial eligibility date, and zero otherwise. Employee-level independent variables include age category dummy variables (omitted category is ages 18-25); account holder location dummy variables (omitted category is account holder lives in an urban Oregon zip code); OregonSaves job number 2 or 3+ dummy variables; and an employee $i$ terminated in or before month $t$ dummy variable. Employer-level independent variables include firm size (natural logarithm of the number of employees when enrolling) and dummy variables indicating whether the employer joined OregonSaves during the pilot phase, whether the employer registered after the OregonSaves deadline based on firm size, and whether Industry-level independent variables include median employee income within the industry in month $t$ and the standard deviation of employee income within the industry in month $t$. Column (1) includes the full sample of employees and includes the control for whether the employer has processed payroll for at least on employee through month $t$; columns (2) through (4) includes only employees for whom this variable equals one. Column (4) includes the fraction of employee i's coworkers that had a positive account balance in month $t-1$. All columns include year-month fixed effects. Columns (3) and (4) include industry fixed effects. Standard errors cluster on employer. Statistical significance at the 1-percent, 5-percent, and 10-percent levels is indicated by $* * *, * *$, and *, respectively. Source: Authors calculations.

\begin{tabular}{|c|c|c|c|c|c|}
\hline & \multicolumn{5}{|c|}{ Predicting positive balance 3 months after eligibility } \\
\hline & (1) & (2) & (3) & (4) & (5) \\
\hline \multirow[t]{2}{*}{ Age $26-35(t)$} & $11.84 * \approx$ & $14.20 * *$ & $14.77 * \approx$ & $13.82 * *$ & $12.16 * *$ \\
\hline & $(0.73)$ & $(0.88)$ & $(0.71)$ & $(0.66)$ & $(0.61)$ \\
\hline \multirow[t]{2}{*}{ Age $36-45(t)$} & $10.69 * *$ & $13.15 * \approx$ & $14.00 * \approx$ & $13.64 * \approx$ & $12.25 \approx *$ \\
\hline & $(0.80)$ & $(0.98)$ & $(0.76)$ & $(0.69)$ & $(0.65)$ \\
\hline \multirow[t]{2}{*}{ Age $46-55(t)$} & $11.68 * *$ & $14.93 * *$ & $15.97 \approx *$ & $15.97 * *$ & $14.60 * \approx$ \\
\hline & $(0.82)$ & $(1.02)$ & $(0.80)$ & $(0.73)$ & $(0.76)$ \\
\hline \multirow[t]{2}{*}{ Age $56-65(t)$} & $13.52 * *$ & $17.34 * \approx$ & $18.39 * 8$ & $18.86 * *$ & $15.91 * 8$ \\
\hline & $(0.87)$ & $(1.07)$ & $(0.83)$ & $(0.78)$ & $(0.83)$ \\
\hline \multirow[t]{2}{*}{ Age $66-75(t)$} & $11.61 * *$ & $15.13 * *$ & $15.32 \approx$ & $15.70 * \approx$ & $12.69 \approx$ \\
\hline & (1.15) & $(1.54)$ & $(1.41)$ & $(1.33)$ & $(1.34)$ \\
\hline \multirow[t]{2}{*}{ Age $>75(t)$} & 2.71 & 3.02 & $6.27^{*}$ & $8.11 \approx$ & $9.69 * *$ \\
\hline & $(2.63)$ & (3.79) & $(3.60)$ & (3.69) & $(3.49)$ \\
\hline \multirow[t]{2}{*}{ Account holder in rural Oregon? $(t)$} & -1.27 & -1.40 & -0.24 & -0.13 & $0.98 *$ \\
\hline & $(0.83)$ & $(1.03)$ & $(0.90)$ & $(0.77)$ & $(0.57)$ \\
\hline \multirow[t]{2}{*}{ Account holder live outside Oregon? $(\mathrm{t})$} & $-10.79 * *$ & $-13.80 * \approx$ & $-11.91 \approx$ & $-10.06 * \approx$ & $-2.42 *$ \\
\hline & (1.93) & $(2.18)$ & $(1.69)$ & $(1.52)$ & $(1.33)$ \\
\hline \multirow[t]{2}{*}{ OregonSaves job number $2(t)$} & $9.52 * \approx$ & $6.15 * \approx$ & $6.65 * 8$ & $6.81 * \approx$ & $9.39 * *$ \\
\hline & $(0.76)$ & $(0.82)$ & $(0.70)$ & $(0.63)$ & $(0.56)$ \\
\hline \multirow[t]{2}{*}{ OregonSaves job number $3+(t)$} & -2.23 & -7.02 & 0.49 & 1.25 & $15.61 *$ \\
\hline & $(4.70)$ & $(4.73)$ & $(2.88)$ & $(2.84)$ & $(1.28)$ \\
\hline \multirow[t]{2}{*}{ Employee terminated? $(\mathrm{t})$} & $-29.95 * *$ & $-32.90 * \approx$ & $-33.47 * \approx$ & $-31.64 * 8$ & $-38.06 * 8$ \\
\hline & (1.11) & $(1.08)$ & $(0.91)$ & $(0.87)$ & $(0.86)$ \\
\hline \multirow{2}{*}{$\begin{array}{l}\text { Average county unemployment } \\
\text { rate (t-3 to } t-1)\end{array}$} & $1.60 * \approx$ & $1.89 *$ & $1.65 * \approx$ & $1.35 *$ & 0.47 \\
\hline & $(0.62)$ & $(0.78)$ & $(0.63)$ & $(0.54)$ & $(0.51)$ \\
\hline \multirow{2}{*}{$\begin{array}{l}\text { Fraction of EEs with positive balance } \\
\text { within ER (t-1) }\end{array}$} & & & & $54.84 * *$ & \\
\hline & & & & $(2.60)$ & \\
\hline \multirow[t]{2}{*}{ Ln (number of employees) } & $-7.49 * \approx$ & $-8.20 * *$ & $-7.17 * * *$ & $-5.64 * \approx$ & \\
\hline & (1.16) & $(1.26)$ & $(1.00)$ & $(0.90)$ & \\
\hline \multirow[t]{2}{*}{ Pilot employer? (t) } & $-24.25 * *$ & $-24.04 * \approx$ & $-20.69 * 8$ & $-19.73 * *$ & \\
\hline & $(8.28)$ & $(8.25)$ & $(6.65)$ & $(4.94)$ & \\
\hline \multirow[t]{2}{*}{ Employer registered late? $(\mathrm{t})$} & 1.58 & 0.50 & -0.56 & 0.31 & \\
\hline & $(1.58)$ & (1.93) & $(1.58)$ & $(1.36)$ & \\
\hline \multirow[t]{2}{*}{ Employer processed payroll? (t) } & $62.52 * *$ & & & & \\
\hline & $(0.91)$ & & & & \\
\hline \multirow[t]{2}{*}{ Median industry income $(t)$} & $-2.53 *$ & $-3.51 *$ & 5.62 & 3.89 & \\
\hline & $(1.06)$ & $(1.42)$ & $(5.75)$ & (5.59) & \\
\hline \multirow[t]{2}{*}{ SD industry income $(t)$} & 0.24 & 0.51 & 0.26 & 0.35 & \\
\hline & $(0.81)$ & $(1.00)$ & $(1.00)$ & $(0.88)$ & \\
\hline
\end{tabular}




\begin{tabular}{|c|c|c|c|c|c|}
\hline Limited to ERs that processed contrib.? & -. & Yes & Yes & Yes & Yes \\
\hline Limited to accounts in OR or WA? & Yes & Yes & Yes & Yes & Yes \\
\hline Year-month FE? & Yes & Yes & Yes & Yes & Yes \\
\hline Industry FE? & -- & -- & Yes & Yes & -. \\
\hline Employer FE? & -- & -- & -- & -- & Yes \\
\hline $\mathrm{N}$ & 126,778 & 99,987 & 99,987 & 95,670 & 100,467 \\
\hline Adj. R2 & 0.2883 & 0.1637 & 0.1854 & 0.2219 & 0.3126 \\
\hline Mean Dependent: & 42.52 & 53.07 & 53.07 & 52.93 & 53.07 \\
\hline
\end{tabular}




\section{Table 7: Distribution of OregonSaves Contribution Rates}

In this table, we describe the distribution of OregonSaves contribution rates. In columns (1) and (2), we focus on the sample of employees three months after the initial eligibility date, with one observation per employee. Because employees who opt out have a contribution rate of 0\%, column (2) excludes employees who have formally opted out. In columns (3) and (4), the unit of observation is employee-month. Column (3) focuses on the entire sample of employee-months while column (4) focuses on employees who are active, eligible, have an open account, and have not formally opted out in month $t$. Source: Authors calculations.

\begin{tabular}{|c|c|c|c|c|c|c|c|c|}
\hline \multirow{5}{*}{$\begin{array}{l}\text { Current } \\
\text { Rate } \\
\end{array}$} & \multicolumn{4}{|c|}{ Employee } & \multicolumn{4}{|c|}{ Employee-month } \\
\hline & \multirow{3}{*}{\multicolumn{2}{|c|}{ All }} & & & & \multicolumn{2}{|c|}{ Active \& Eligible } \\
\hline & & & & & & & \multicolumn{2}{|c|}{ \& Account Open } \\
\hline & & & \multicolumn{2}{|c|}{ Not Opt Out } & \multicolumn{2}{|l|}{ All } & \multicolumn{2}{|c|}{$\&$ Not Opted Out } \\
\hline & \multicolumn{2}{|l|}{ (1) } & \multicolumn{2}{|l|}{$(2)$} & \multicolumn{2}{|l|}{ (3) } & \multicolumn{2}{|l|}{ (4) } \\
\hline $0 \%$ & 95,976 & $43.21 \%$ & 5,163 & $3.93 \%$ & $1,696,106$ & $44.56 \%$ & 55,428 & $4.57 \%$ \\
\hline $1 \%$ & 972 & $0.44 \%$ & 972 & $0.74 \%$ & 16,806 & $0.44 \%$ & 13,169 & $1.09 \%$ \\
\hline $2 \%$ & 888 & $0.40 \%$ & 888 & $0.68 \%$ & 16,930 & $0.44 \%$ & 13,706 & $1.13 \%$ \\
\hline $3 \%$ & 792 & $0.36 \%$ & 792 & $0.60 \%$ & 15,970 & $0.42 \%$ & 13,085 & $1.08 \%$ \\
\hline $4 \%$ & 94 & $0.04 \%$ & 94 & $0.07 \%$ & 4,512 & $0.12 \%$ & 3,800 & $0.31 \%$ \\
\hline $5 \%$ & 122,455 & $55.13 \%$ & 122,455 & $93.26 \%$ & $1,847,534$ & $48.54 \%$ & 942,463 & $77.67 \%$ \\
\hline $6 \%$ & 70 & $0.03 \%$ & 70 & $0.05 \%$ & 168,011 & $4.41 \%$ & 136,476 & $11.25 \%$ \\
\hline $7 \%$ & 104 & $0.05 \%$ & 104 & $0.08 \%$ & 22,684 & $0.60 \%$ & 20,373 & $1.68 \%$ \\
\hline $8 \%$ & 85 & $0.04 \%$ & 85 & $0.06 \%$ & 2,221 & $0.06 \%$ & 1,949 & $0.16 \%$ \\
\hline $9 \%$ & 5 & $0.00 \%$ & 5 & $0.00 \%$ & 615 & $0.02 \%$ & 559 & $0.05 \%$ \\
\hline $10 \%$ & 517 & $0.23 \%$ & 517 & $0.39 \%$ & 11,361 & $0.30 \%$ & 9,359 & $0.77 \%$ \\
\hline $11 \%-15 \%$ & 75 & $0.03 \%$ & 75 & $0.06 \%$ & 1874 & $0.05 \%$ & 1548 & $0.13 \%$ \\
\hline $16 \%-20 \%$ & 24 & $0.01 \%$ & 24 & $0.02 \%$ & 662 & $0.02 \%$ & 548 & $0.05 \%$ \\
\hline $21 \%-30 \%$ & 22 & $0.01 \%$ & 22 & $0.02 \%$ & 469 & $0.01 \%$ & 412 & $0.03 \%$ \\
\hline $31 \%-40 \%$ & 4 & $0.00 \%$ & 4 & $0.00 \%$ & 50 & $0.00 \%$ & 50 & $0.00 \%$ \\
\hline $41 \%-50 \%$ & 15 & $0.01 \%$ & 15 & $0.01 \%$ & 341 & $0.01 \%$ & 306 & $0.03 \%$ \\
\hline $51 \%-99 \%$ & 0 & $0.00 \%$ & 0 & $0.00 \%$ & 25 & $0.00 \%$ & 25 & $0.00 \%$ \\
\hline $100 \%$ & 14 & $0.01 \%$ & 14 & $0.01 \%$ & 213 & $0.01 \%$ & 183 & $0.02 \%$ \\
\hline All & 222,115 & & 131,302 & & $3,806,384$ & & $1,213,465$ & \\
\hline
\end{tabular}


Table 8: Frequency of Monthly Changes in Contribution Rates among Active, Eligible Employees with Open Accounts

In this table, we provide evidence on persistence in contribution rates across months. Similar to column (4) of Table 7, the unit of observation is employee-month and the sample is limited to employees who are active, eligible, have an open account, and have not formally opted out in month $t-1$. For each lagged contribution rate, we report the number of employee-months with the current contribution rate, as well as the percent decreasing or increasing their contribution rate. Because we combine all contribution rates greater than $7 \%$ into a single category, we do not report percentage increase within this row. Source: Authors calculations.

\begin{tabular}{|c|c|c|c|c|c|c|c|c|c|c|c|c|}
\hline \multirow[b]{2}{*}{ Lagged Rate } & \multicolumn{9}{|c|}{ Current Rate } & \multirow[b]{2}{*}{ All } & \multirow[b]{2}{*}{$\%$ Decrease } & \multirow[b]{2}{*}{$\%$ Increase } \\
\hline & $0 \%$ & $1 \%$ & $2 \%$ & $3 \%$ & $4 \%$ & $5 \%$ & $6 \%$ & $7 \%$ & $>7 \%$ & & & \\
\hline $0 \%$ & 51,239 & 9 & 8 & 7 & 3 & 21 & 1 & 2 & 9 & 51,299 & -- & $0.1 \%$ \\
\hline $1 \%$ & 131 & 11,779 & 363 & 33 & 7 & 32 & 1 & 2 & 9 & 12,357 & $1.1 \%$ & $3.6 \%$ \\
\hline $2 \%$ & 151 & 62 & 12,161 & 444 & 17 & 14 & 3 & 2 & 10 & 12,864 & $1.7 \%$ & $3.8 \%$ \\
\hline $3 \%$ & 163 & 63 & 34 & 11,497 & 420 & 40 & 5 & 4 & 3 & 12,229 & $2.1 \%$ & $3.9 \%$ \\
\hline $4 \%$ & 40 & 14 & 24 & 14 & 3,218 & 129 & 7 & 2 & 9 & 3,457 & $2.7 \%$ & $4.3 \%$ \\
\hline $5 \%$ & 19,385 & 483 & 449 & 323 & 50 & 838,895 & 23,394 & 107 & 539 & 883,625 & $2.3 \%$ & $2.7 \%$ \\
\hline $6 \%$ & 908 & 30 & 27 & 48 & 29 & 72 & 116,850 & 5,204 & 116 & 123,284 & $0.9 \%$ & $4.3 \%$ \\
\hline $7 \%$ & 127 & 6 & 8 & 13 & 6 & 23 & 5 & 15,477 & 139 & 15,804 & $1.2 \%$ & $0.1 \%$ \\
\hline$>7 \%$ & 236 & 29 & 11 & 17 & 9 & 127 & 12 & 10 & 13,470 & 13,921 & $3.2 \%$ & -- \\
\hline All & 72,380 & 12,475 & 13,085 & 12,396 & 3,759 & 839,353 & 140,278 & 20,810 & 14,304 & $1,128,840$ & $2.0 \%$ & $2.8 \%$ \\
\hline
\end{tabular}


Table 9: Growth of OregonSaves, August 2018 - April 2020

The sample is limited to open accounts in month $t$. We report the total number of dollars invested in OregonSaves at the end of each month, as well as the total net flows (inflows minus outflows), inflows, and outflows during the month. Percent net flow is the net flow during month $t$ scaled by total assets in month $t-1$. Percent inflow and outflow are defined similarly. The "\% Liquid Reserve” is the fraction of all OregonSaves assets invested in the State Street Institutional Liquid Reserve Fund, the initial default investment option for each account. Source: Authors calculations.

\begin{tabular}{|c|c|c|c|c|c|c|c|c|}
\hline Date & $\begin{array}{r}\text { Total } \\
\text { assets }\end{array}$ & $\begin{array}{r}\text { Total } \\
\text { net flow }\end{array}$ & $\begin{array}{r}\text { Total } \\
\text { inflow }\end{array}$ & $\begin{array}{l}\text { Total } \\
\text { outflow }\end{array}$ & $\begin{array}{l}\text { Percent } \\
\text { net flow }\end{array}$ & $\begin{array}{l}\text { Percent } \\
\text { inflow }\end{array}$ & $\begin{array}{l}\text { Percent } \\
\text { outflow }\end{array}$ & $\begin{array}{l}\% \text { Liquic } \\
\text { Reserve }\end{array}$ \\
\hline Aug 2018 & $6,679,928$ & $1,074,570$ & $1,287,967$ & $-213,397$ & $19.3 \%$ & $23.1 \%$ & $-3.8 \%$ & $86.4 \%$ \\
\hline Sep 2018 & $7,730,532$ & $1,034,423$ & $1,231,143$ & $-196,720$ & $15.5 \%$ & $18.4 \%$ & $-2.9 \%$ & $84.7 \%$ \\
\hline Oct 2018 & $8,814,097$ & $1,151,576$ & $1,447,061$ & $-295,485$ & $14.9 \%$ & $18.7 \%$ & $-3.8 \%$ & $83.2 \%$ \\
\hline Nov 2018 & $9,910,995$ & $1,052,093$ & 1,348,217 & $-296,124$ & $11.9 \%$ & $15.3 \%$ & $-3.4 \%$ & $80.8 \%$ \\
\hline Dec 2018 & $10,948,439$ & 1,131,755 & $1,427,083$ & $-295,328$ & $11.4 \%$ & $14.4 \%$ & $-3.0 \%$ & $79.1 \%$ \\
\hline Jan 2019 & $12,531,133$ & $1,372,018$ & $1,753,164$ & $-381,146$ & $12.5 \%$ & $16.0 \%$ & $-3.5 \%$ & $75.9 \%$ \\
\hline Feb 2019 & $14,164,566$ & $1,538,361$ & $1,872,047$ & $-333,686$ & $12.3 \%$ & $14.9 \%$ & $-2.7 \%$ & $74.2 \%$ \\
\hline Mar 2019 & $16,211,620$ & $1,949,131$ & $2,294,651$ & $-345,520$ & $13.8 \%$ & $16.2 \%$ & $-2.4 \%$ & $72.9 \%$ \\
\hline Apr 2019 & $18,420,364$ & $2,055,547$ & $2,520,999$ & $-465,452$ & $12.7 \%$ & $15.6 \%$ & $-2.9 \%$ & $71.5 \%$ \\
\hline May 2019 & $20,380,644$ & $2,168,732$ & $2,677,598$ & $-508,866$ & $11.8 \%$ & $14.5 \%$ & $-2.8 \%$ & $71.5 \%$ \\
\hline Jun 2019 & $22,780,423$ & $2,039,662$ & $2,601,049$ & $-561,387$ & $10.0 \%$ & $12.8 \%$ & $-2.8 \%$ & $69.8 \%$ \\
\hline Jul 2019 & $25,487,492$ & $2,638,161$ & $3,328,270$ & $-690,109$ & $11.6 \%$ & $14.6 \%$ & $-3.0 \%$ & $69.3 \%$ \\
\hline Aug 2019 & $28,541,770$ & $3,067,188$ & $3,918,247$ & $-851,059$ & $12.0 \%$ & $15.4 \%$ & $-3.3 \%$ & $68.8 \%$ \\
\hline Sep 2019 & $31,326,977$ & $2,634,966$ & $3,297,416$ & $-662,450$ & $9.2 \%$ & $11.6 \%$ & $-2.3 \%$ & $68.2 \%$ \\
\hline Oct 2019 & $34,559,000$ & $2,973,977$ & $3,808,450$ & $-834,473$ & $9.5 \%$ & $12.2 \%$ & $-2.7 \%$ & $67.3 \%$ \\
\hline Nov 2019 & $37,572,465$ & $2,713,452$ & $3,463,042$ & $-749,590$ & $7.9 \%$ & $10.0 \%$ & $-2.2 \%$ & $66.2 \%$ \\
\hline Dec 2019 & $40,955,951$ & $3,014,223$ & $3,930,297$ & $-916,074$ & $8.0 \%$ & $10.5 \%$ & $-2.4 \%$ & $65.1 \%$ \\
\hline Jan 2020 & $43,800,314$ & $2,852,497$ & $4,065,011$ & $-1,212,514$ & $7.0 \%$ & $9.9 \%$ & $-3.0 \%$ & $64.8 \%$ \\
\hline Feb 2020 & $45,924,890$ & $3,201,617$ & $4,862,348$ & $-1,660,731$ & $7.3 \%$ & $11.1 \%$ & $-3.8 \%$ & $60.7 \%$ \\
\hline Mar 2020 & $46,711,651$ & $3,188,054$ & $4,567,289$ & $-1,379,235$ & $6.9 \%$ & $9.9 \%$ & $-3.0 \%$ & $61.5 \%$ \\
\hline Apr 2020 & $51,054,705$ & $2,485,249$ & $3,202,234$ & $-716,985$ & $5.3 \%$ & $6.9 \%$ & $-1.5 \%$ & $58.1 \%$ \\
\hline
\end{tabular}


Table 10: Account-Level OregonSaves Summary Statistics by Month, August 2018 - April 2020

The sample is limited to open accounts in month $t$. The unit of observation is the account of participant $i$. We report the number of open accounts, the number of open accounts with a positive balance at the end of month $t$, the average account balance at the end of month $t$ (excluding zeros), the fraction of accounts with any inflow, any outflow, or both an inflow and an outflow during month $t$, the average net flow, inflow, and outflow during month $t$ (excluding zeros), and the average fraction of account balances invested in the State Street Institutional Liquid Reserve Fund, the default investment option for the first $\$ 1,000$ in OregonSaves contributions. Source: Authors calculations.

\begin{tabular}{|c|c|c|c|c|c|c|c|c|c|c|}
\hline Date & $\begin{array}{l}\text { Number } \\
\text { of open } \\
\text { accounts }\end{array}$ & $\begin{array}{r}\text { Open } \\
\text { account } \\
\text { \& positive } \\
\text { balance }\end{array}$ & $\begin{array}{r}\text { Average } \\
\text { account } \\
\text { balance } \\
\text { (excl. 0) }\end{array}$ & $\begin{array}{r}\% \text { Accounts } \\
\text { with any } \\
\text { inflow }\end{array}$ & $\begin{array}{r}\% \text { Accounts } \\
\text { with any } \\
\text { outflow }\end{array}$ & $\begin{array}{r}\% \text { Accounts } \\
\text { with both } \\
\text { inflow and } \\
\text { outflow }\end{array}$ & $\begin{array}{l}\text { Average } \\
\text { net flow } \\
\text { (excl. 0) }\end{array}$ & $\begin{array}{r}\text { Average } \\
\text { inflow } \\
\text { (excl. 0) }\end{array}$ & $\begin{array}{l}\text { Average } \\
\text { outflow } \\
\text { (excl. 0) }\end{array}$ & $\begin{array}{l}\text { Average } \\
\% \text { Liquid } \\
\text { Reserve }\end{array}$ \\
\hline Aug 2018 & 19,078 & 17,830 & 374.65 & $65.6 \%$ & $3.2 \%$ & $2.3 \%$ & 84.93 & 102.98 & -354.48 & $96.8 \%$ \\
\hline Sep 2018 & 20,580 & 19,158 & 403.51 & $60.6 \%$ & $2.6 \%$ & $1.9 \%$ & 82.14 & 98.64 & -371.87 & $96.2 \%$ \\
\hline Oct 2018 & 21,926 & 20,256 & 435.14 & $58.1 \%$ & $3.8 \%$ & $3.0 \%$ & 89.50 & 113.64 & -357.73 & $95.4 \%$ \\
\hline Nov 2018 & 23,302 & 21,413 & 462.85 & $56.0 \%$ & $2.7 \%$ & $2.1 \%$ & 79.91 & 103.38 & -470.04 & $94.4 \%$ \\
\hline Dec 2018 & 24,976 & 22,883 & 478.45 & $54.3 \%$ & $2.5 \%$ & $1.8 \%$ & 82.52 & 105.13 & -479.43 & $93.8 \%$ \\
\hline Jan 2019 & 28,524 & 26,054 & 480.97 & $55.4 \%$ & $2.8 \%$ & $1.9 \%$ & 85.81 & 111.04 & -480.64 & $93.3 \%$ \\
\hline Feb 2019 & 32,516 & 29,770 & 475.80 & $55.9 \%$ & $2.2 \%$ & $1.5 \%$ & 83.78 & 102.92 & -457.10 & $93.0 \%$ \\
\hline Mar 2019 & 36,012 & 32,984 & 491.50 & $58.0 \%$ & $2.3 \%$ & $1.8 \%$ & 92.77 & 109.83 & -419.83 & $92.7 \%$ \\
\hline Apr 2019 & 38,582 & 35,173 & 523.71 & $55.7 \%$ & $2.4 \%$ & $1.7 \%$ & 94.66 & 117.36 & -504.28 & $92.3 \%$ \\
\hline May 2019 & 41,048 & 37,266 & 546.90 & $55.2 \%$ & $2.4 \%$ & $1.9 \%$ & 95.02 & 118.23 & -515.05 & $91.9 \%$ \\
\hline Jun 2019 & 44,803 & 40,724 & 559.39 & $54.1 \%$ & $2.3 \%$ & $1.7 \%$ & 83.46 & 107.32 & -552.00 & $91.6 \%$ \\
\hline Jul 2019 & 49,410 & 44,774 & 569.25 & $54.4 \%$ & $2.7 \%$ & $2.0 \%$ & 97.21 & 123.75 & -522.81 & $91.5 \%$ \\
\hline Aug 2019 & 53,237 & 48,171 & 592.51 & $53.4 \%$ & $2.3 \%$ & $1.8 \%$ & 107.12 & 137.70 & -692.48 & $91.3 \%$ \\
\hline Sep 2019 & 56,211 & 50,753 & 617.24 & $51.0 \%$ & $2.1 \%$ & $1.7 \%$ & 91.24 & 114.93 & -549.30 & $91.0 \%$ \\
\hline Oct 2019 & 59,025 & 53,087 & 650.99 & $50.5 \%$ & $2.6 \%$ & $2.0 \%$ & 98.71 & 127.68 & -542.57 & $90.5 \%$ \\
\hline Nov 2019 & 61,633 & 55,311 & 679.29 & $47.6 \%$ & $2.1 \%$ & $1.6 \%$ & 91.75 & 118.00 & -590.69 & $90.2 \%$ \\
\hline Dec 2019 & 65,372 & 58,619 & 698.68 & $48.9 \%$ & $2.5 \%$ & $2.0 \%$ & 93.53 & 122.91 & -564.09 & $89.9 \%$ \\
\hline Jan 2020 & 70,063 & 62,424 & 701.66 & $48.5 \%$ & $2.9 \%$ & $1.9 \%$ & 82.67 & 119.71 & -604.44 & $89.7 \%$ \\
\hline Feb 2020 & 73,257 & 65,020 & 706.32 & $47.0 \%$ & $3.6 \%$ & $2.8 \%$ & 91.56 & 141.13 & -622.93 & $88.2 \%$ \\
\hline Mar 2020 & 75,496 & 66,717 & 700.15 & $45.6 \%$ & $3.0 \%$ & $2.2 \%$ & 91.19 & 132.60 & -613.27 & $87.0 \%$ \\
\hline Apr 2020 & 77,007 & 67,731 & 753.79 & $34.4 \%$ & $1.6 \%$ & $0.7 \%$ & 91.67 & 120.94 & -590.11 & $86.2 \%$ \\
\hline
\end{tabular}




\section{Table 11: Evolution of Account Balances Based on Employee Status}

In this table, the unit of observation is account $i$ in month $t$. We limit the sample to accounts for which the first contribution is August 2018 or later (which explains why the number of open accounts in the first column is less than 70,077). We begin following an account when it makes its first contribution into OregonSaves and then track the account forward up to 18 months. Because the number of OregonSaves participants is growing over time, we necessarily have fewer observations as we move from month $\mathrm{t}$ of the initial contribution to month $t+17$. The fraction of participants classified by (one or more of their employers) as active at the end of month t falls from $96.8 \%$ to $61.5 \%$. We report account statistics separately for active and inactive employees. For example, 11 months after their initial contribution into OregonSaves there are 16,508 OregonSaves participants classified as active (at one or more employers) and 7,109 classified as inactive. We report the fraction of open accounts with positive balances, with any inflows during the month, with any outflows during the month, and average balance at the end of the month (including zeros). Source: Authors calculations.

\begin{tabular}{|c|c|c|c|c|c|c|c|c|c|c|c|c|}
\hline \multirow{2}{*}{$\begin{array}{r}\text { Months } \\
\text { since } \\
\text { initial } \\
\text { contribution }\end{array}$} & \multirow[b]{2}{*}{$\begin{array}{l}\text { Number } \\
\text { of open } \\
\text { accounts }\end{array}$} & \multirow[b]{2}{*}{$\begin{array}{l}\% \text { still } \\
\text { active }\end{array}$} & \multicolumn{5}{|c|}{ Employee classified as active in month $t$} & \multicolumn{5}{|c|}{ Employee classified as inactive in month $\mathrm{t}$} \\
\hline & & & $\begin{array}{l}\text { Number } \\
\text { of open } \\
\text { accounts }\end{array}$ & $\begin{array}{l}\% \text { with } \\
\text { positive } \\
\text { balance }\end{array}$ & $\begin{array}{l}\% \text { with } \\
\text { inflow }\end{array}$ & $\begin{array}{l}\% \text { with } \\
\text { outflow }\end{array}$ & $\begin{array}{l}\text { Average } \\
\text { balance } \\
\text { (incl. 0) }\end{array}$ & $\begin{array}{r}\text { Number } \\
\text { of open } \\
\text { accounts }\end{array}$ & $\begin{array}{l}\% \text { with } \\
\text { positive } \\
\text { balance }\end{array}$ & $\begin{array}{l}\% \text { with } \\
\text { inflow }\end{array}$ & $\begin{array}{l}\% \text { with } \\
\text { outflow }\end{array}$ & $\begin{array}{l}\text { Average } \\
\text { balance } \\
\text { (incl. 0) }\end{array}$ \\
\hline 1 & 59,043 & $96.8 \%$ & 57,171 & $99.7 \%$ & $99.9 \%$ & $0.5 \%$ & 89 & 1,872 & $99.5 \%$ & $99.8 \%$ & $0.9 \%$ & 203 \\
\hline 2 & 57,547 & $93.3 \%$ & 53,695 & $98.2 \%$ & $84.2 \%$ & $2.7 \%$ & 172 & 3,852 & $97.6 \%$ & $48.4 \%$ & $3.1 \%$ & 162 \\
\hline 3 & 55,332 & $90.0 \%$ & 49,820 & $97.1 \%$ & $78.2 \%$ & $2.3 \%$ & 255 & 5,512 & $96.4 \%$ & $27.9 \%$ & $2.3 \%$ & 169 \\
\hline 4 & 52,179 & $86.5 \%$ & 45,146 & $96.2 \%$ & $72.8 \%$ & $2.3 \%$ & 335 & 7,033 & $94.9 \%$ & $20.5 \%$ & $2.3 \%$ & 186 \\
\hline 5 & 47,559 & $83.6 \%$ & 39,752 & $95.2 \%$ & $69.1 \%$ & $2.4 \%$ & 411 & 7,807 & $93.7 \%$ & $13.9 \%$ & $1.9 \%$ & 204 \\
\hline 6 & 43,885 & $81.0 \%$ & 35,525 & $94.4 \%$ & $66.7 \%$ & $2.7 \%$ & 484 & 8,360 & $92.5 \%$ & $11.3 \%$ & $1.6 \%$ & 218 \\
\hline 7 & 41,320 & $79.0 \%$ & 32,653 & $93.7 \%$ & $63.9 \%$ & $2.7 \%$ & 555 & 8,667 & $91.3 \%$ & $9.7 \%$ & $1.8 \%$ & 236 \\
\hline 8 & 38,558 & $76.9 \%$ & 29,645 & $93.1 \%$ & $61.8 \%$ & $3.0 \%$ & 622 & 8,913 & $90.5 \%$ & $8.5 \%$ & $1.6 \%$ & 250 \\
\hline 9 & 35,621 & $75.2 \%$ & 26,776 & $92.4 \%$ & $59.5 \%$ & $3.1 \%$ & 687 & 8,845 & $89.8 \%$ & $8.6 \%$ & $1.4 \%$ & 275 \\
\hline 10 & 31,856 & $73.6 \%$ & 23,444 & $91.9 \%$ & $56.8 \%$ & $3.0 \%$ & 743 & 8,412 & $89.3 \%$ & $8.3 \%$ & $1.3 \%$ & 282 \\
\hline 11 & 27,332 & $71.6 \%$ & 19,577 & $91.5 \%$ & $55.3 \%$ & $3.2 \%$ & 807 & 7,755 & $88.5 \%$ & $7.3 \%$ & $1.3 \%$ & 299 \\
\hline 12 & 23,617 & $69.9 \%$ & 16,508 & $90.9 \%$ & $56.0 \%$ & $3.5 \%$ & 865 & 7,109 & $87.7 \%$ & $7.2 \%$ & $1.5 \%$ & 311 \\
\hline 13 & 21,190 & $68.8 \%$ & 14,569 & $90.5 \%$ & $54.7 \%$ & $3.8 \%$ & 916 & 6,621 & $86.8 \%$ & $6.6 \%$ & $1.6 \%$ & 322 \\
\hline 14 & 18,627 & $67.6 \%$ & 12,588 & $89.9 \%$ & $51.5 \%$ & $4.1 \%$ & 969 & 6,039 & $86.5 \%$ & $6.5 \%$ & $1.4 \%$ & 340 \\
\hline 15 & 15,178 & $65.3 \%$ & 9,917 & $90.2 \%$ & $51.9 \%$ & $3.4 \%$ & 1,040 & 5,261 & $85.6 \%$ & $6.1 \%$ & $1.5 \%$ & 352 \\
\hline 16 & 11,211 & $65.0 \%$ & 7,284 & $89.6 \%$ & $49.6 \%$ & $3.4 \%$ & 1,078 & 3,927 & $85.3 \%$ & $4.8 \%$ & $1.5 \%$ & 356 \\
\hline 17 & 7,714 & $63.7 \%$ & 4,910 & $89.7 \%$ & $46.9 \%$ & $2.9 \%$ & 1,070 & 2,804 & $84.6 \%$ & $4.4 \%$ & $1.6 \%$ & 363 \\
\hline 18 & 6,053 & $61.5 \%$ & 3,724 & $89.2 \%$ & $48.1 \%$ & $3.4 \%$ & 1,132 & 2,329 & $84.2 \%$ & $4.4 \%$ & $1.4 \%$ & 370 \\
\hline
\end{tabular}




\section{Table 12: Employee Status and Average OregonSaves Account Balance}

In this table, the unit of observation is account $i$ in month $t$. As in Table 11, we limit the sample to accounts for which the first contribution is August 2018 or later. We begin following an account when it makes its first contribution into OregonSaves and then track the account forward up to 18 months. Each month, we report the fraction of participants classified by (one or more of their employers) as active at the end of month $t$ and the average account balance, separately by age range. Source: Authors calculations.

\begin{tabular}{|c|c|c|c|c|c|c|c|c|c|c|c|c|c|c|}
\hline \multirow{2}{*}{$\begin{array}{r}\text { Months } \\
\text { since initial } \\
\text { contribution }\end{array}$} & \multicolumn{7}{|c|}{ Fraction of accounts where employee is classified as active in month $t$} & \multicolumn{7}{|c|}{ Average balance (incl. 0) } \\
\hline & $<26$ & $26-35$ & $36-45$ & $46-55$ & $56-65$ & $66-75$ & $>75$ & $<26$ & $26-35$ & $36-45$ & $46-55$ & $56-65$ & $66-75$ & $>75$ \\
\hline 1 & $96.2 \%$ & $97.0 \%$ & $96.8 \%$ & $97.4 \%$ & $97.2 \%$ & $97.6 \%$ & $99.2 \%$ & 65.26 & 88.73 & 101.07 & 111.03 & 146.87 & 89.27 & 61.48 \\
\hline 2 & $91.5 \%$ & $93.2 \%$ & $93.8 \%$ & $94.8 \%$ & $95.1 \%$ & $95.6 \%$ & $96.7 \%$ & 123.26 & 165.68 & 191.84 & 209.97 & 244.57 & 155.61 & 111.96 \\
\hline 3 & $87.3 \%$ & $89.5 \%$ & $91.1 \%$ & $92.8 \%$ & $93.2 \%$ & $93.3 \%$ & $96.5 \%$ & 175.81 & 238.25 & 277.05 & 305.82 & 337.35 & 223.70 & 156.69 \\
\hline 4 & $82.7 \%$ & $85.6 \%$ & $88.0 \%$ & $90.3 \%$ & $91.0 \%$ & $91.6 \%$ & $96.0 \%$ & 222.60 & 305.09 & 353.78 & 394.82 & 432.93 & 292.48 & 222.19 \\
\hline 5 & $78.6 \%$ & $82.7 \%$ & $85.4 \%$ & $88.2 \%$ & $89.1 \%$ & $90.3 \%$ & $95.7 \%$ & 263.19 & 361.24 & 425.81 & 477.48 & 520.40 & 358.94 & 285.55 \\
\hline 6 & $75.4 \%$ & $79.8 \%$ & $83.0 \%$ & $86.6 \%$ & $86.7 \%$ & $88.8 \%$ & $96.3 \%$ & 295.59 & 414.93 & 493.16 & 559.03 & 593.63 & 418.15 & 325.83 \\
\hline 7 & $72.5 \%$ & $77.4 \%$ & $81.8 \%$ & $85.2 \%$ & $85.9 \%$ & $88.2 \%$ & $95.2 \%$ & 326.91 & 462.92 & 556.98 & 632.55 & 675.60 & 478.78 & 381.04 \\
\hline 8 & $69.8 \%$ & $75.3 \%$ & $79.7 \%$ & $83.3 \%$ & $84.4 \%$ & $85.2 \%$ & $95.2 \%$ & 354.20 & 505.94 & 612.77 & 701.75 & 741.65 & 527.05 & 427.60 \\
\hline 9 & $67.7 \%$ & $73.0 \%$ & $78.2 \%$ & $82.5 \%$ & $83.2 \%$ & $84.3 \%$ & $90.9 \%$ & 380.16 & 545.30 & 672.50 & 765.76 & 820.13 & 580.57 & 465.00 \\
\hline 10 & $65.4 \%$ & $71.3 \%$ & $77.2 \%$ & $81.4 \%$ & $81.6 \%$ & $84.2 \%$ & $88.9 \%$ & 406.28 & 579.05 & 716.30 & 826.69 & 820.95 & 643.66 & 478.15 \\
\hline 11 & $63.1 \%$ & $69.3 \%$ & $75.3 \%$ & $79.8 \%$ & $80.2 \%$ & $81.4 \%$ & $86.4 \%$ & 428.92 & 612.02 & 766.34 & 894.69 & 890.25 & 707.74 & 498.58 \\
\hline 12 & $61.3 \%$ & $66.9 \%$ & $74.5 \%$ & $78.4 \%$ & $78.8 \%$ & $78.2 \%$ & $87.7 \%$ & 452.68 & 635.00 & 809.65 & 945.51 & 969.04 & 757.78 & 554.02 \\
\hline 13 & $60.2 \%$ & $65.4 \%$ & $73.7 \%$ & $77.1 \%$ & $77.6 \%$ & $76.5 \%$ & $87.0 \%$ & 467.50 & 653.63 & 839.76 & 992.20 & 1053.38 & 807.72 & 619.87 \\
\hline 14 & $58.7 \%$ & $64.2 \%$ & $72.9 \%$ & $75.6 \%$ & $76.5 \%$ & $74.4 \%$ & $85.4 \%$ & 486.56 & 681.00 & 883.81 & 1027.77 & 1101.28 & 842.07 & 691.06 \\
\hline 15 & $55.7 \%$ & $61.6 \%$ & $70.8 \%$ & $73.4 \%$ & $74.6 \%$ & $75.0 \%$ & $86.8 \%$ & 481.35 & 711.70 & 925.93 & 1072.63 & 1184.77 & 931.61 & 576.71 \\
\hline 16 & $55.2 \%$ & $61.4 \%$ & $70.0 \%$ & $74.3 \%$ & $74.5 \%$ & $76.4 \%$ & $88.9 \%$ & 495.67 & 739.57 & 977.09 & 1122.11 & 1184.33 & 916.11 & 618.93 \\
\hline 17 & $52.9 \%$ & $60.8 \%$ & $68.4 \%$ & $73.7 \%$ & $73.0 \%$ & $76.7 \%$ & $85.7 \%$ & 486.25 & 736.17 & 969.93 & 1089.15 & 1164.20 & 968.20 & 844.14 \\
\hline \multirow[t]{2}{*}{18} & $50.7 \%$ & $57.2 \%$ & $67.1 \%$ & $72.4 \%$ & $70.9 \%$ & $77.5 \%$ & $85.7 \%$ & 487.35 & 752.23 & 980.08 & 1171.95 & 1186.39 & 1005.71 & 887.43 \\
\hline & \multicolumn{7}{|c|}{ Average balance per month (incl. 0) at month 12: } & 37.72 & 52.92 & 67.47 & 78.79 & 80.75 & 63.15 & 46.17 \\
\hline
\end{tabular}




\section{Table 13: Predicting Any Monthly Inflows and Outflows}

In this table, we estimate linear probability models to predict any monthly inflows and outflows. The unit of observation is the account of employee $i$ in month $t$. We limit the sample to accounts for which the first contribution is August 2018 or later. The dependent variable in column (1) equals 100 if there is any inflow into the account in month $t$, and zero otherwise. Similarly, the dependent variable in column (2) equals 100 if there is any outflow from the account in month $t$, and zero otherwise. We include dummy variables to capture whether the employee is listed as being actively employed, whether they were terminated during month $t$ (which reflect either a formal opt out decision or a direct change to the saving rate). We include age category fixed effects (omitted category is ages 18-25); months since the initial contribution fixed effects; date fixed effects; and industry fixed effects. Standard errors cluster on employer. Statistical significance at the 1-percent, 5- percent, and 10-percent levels is indicated by ***, **, and *, respectively. Source: Authors calculations.

\begin{tabular}{|c|c|c|c|c|c|c|}
\hline \multirow[b]{3}{*}{ Active? } & \multirow{2}{*}{\multicolumn{3}{|c|}{$\begin{array}{c}\text { Any inflow in month } t ? \\
\text { (1) }\end{array}$}} & \multirow{2}{*}{\multicolumn{3}{|c|}{$\frac{\text { Any outflow in month } t \text { ? }}{\text { (2) }}$}} \\
\hline & & & & & & \\
\hline & 52.05 & $(3.13)$ & $* *$ & 1.96 & $(0.10)$ & $* \approx$ \\
\hline Terminated this month? & 24.29 & $(3.06)$ & $* *$ & 3.34 & $(0.20)$ & $* * *$ \\
\hline Terminated last month? & -4.84 & $(1.37)$ & $* * *$ & 1.31 & $(0.14)$ & $* * *$ \\
\hline Zero savings rate? & -45.44 & $(3.16)$ & $* *$ & 4.74 & $(0.13)$ & $* \approx *$ \\
\hline Age 26-35 & 4.07 & $(0.53)$ & $* *$ & 0.51 & $(0.08)$ & $* \approx$ \\
\hline Age $36-45$ & 6.43 & $(0.77)$ & $* *$ & 0.54 & $(0.09)$ & $* \approx *$ \\
\hline Age 46-55 & 8.43 & $(0.93)$ & $* *$ & 0.21 & $(0.11)$ & $*$ \\
\hline Age 56-65 & 9.96 & $(1.06)$ & $* *$ & 0.08 & $(0.12)$ & \\
\hline Age 66-75 & 7.69 & $(1.26)$ & $* *$ & -0.11 & $(0.22)$ & \\
\hline Age $>75$ & 4.28 & $(2.48)$ & $*$ & -0.49 & $(0.51)$ & \\
\hline Month 3 & -5.86 & $(0.49)$ & $* *$ & -0.40 & $(0.11)$ & $* * *$ \\
\hline Month 4 & -10.57 & $(0.68)$ & $* *$ & -0.29 & $(0.12)$ & $*$ \\
\hline Month 5 & -14.26 & $(0.83)$ & $* *$ & -0.33 & $(0.12)$ & $* * *$ \\
\hline Month 6 & -16.54 & $(0.93)$ & $* *$ & -0.17 & $(0.13)$ & \\
\hline Month 7 & -18.66 & $(1.05)$ & $* *$ & -0.15 & $(0.13)$ & \\
\hline Month 8 & -20.18 & $(1.15)$ & $* * *$ & -0.02 & $(0.14)$ & \\
\hline Month 9 & -21.00 & $(1.23)$ & $* *$ & 0.00 & $(0.14)$ & \\
\hline Month 10 & -21.97 & $(1.35)$ & $* * *$ & -0.06 & $(0.15)$ & \\
\hline Month 11 & -22.95 & $(1.47)$ & $* * *$ & 0.04 & $(0.17)$ & \\
\hline Month 12 & -22.55 & $(1.57)$ & $* *$ & 0.08 & $(0.18)$ & \\
\hline Month 13 & -22.83 & (1.69) & $* *$ & 0.30 & $(0.20)$ & \\
\hline Month 14 & -24.34 & $(1.84)$ & $* * *$ & 0.50 & $(0.20)$ & $* *$ \\
\hline Month 15 & -23.14 & $(2.01)$ & $* * *$ & 0.16 & $(0.21)$ & \\
\hline Month 16 & -24.02 & $(2.31)$ & $* *$ & 0.26 & $(0.25)$ & \\
\hline Month 17 & -26.99 & $(2.51)$ & $* *$ & -0.31 & $(0.25)$ & \\
\hline Month 18 & -25.92 & $(2.52)$ & $* *$ & -0.30 & $(0.29)$ & \\
\hline Oct 2018 & -4.33 & $(3.21)$ & & 0.27 & $(0.95)$ & \\
\hline Nov 2018 & -1.72 & $(1.84)$ & & -0.01 & $(0.91)$ & \\
\hline Dec 2018 & -2.61 & $(2.35)$ & & -0.27 & $(0.90)$ & \\
\hline Jan 2019 & -3.42 & $(2.50)$ & & 0.43 & $(0.91)$ & \\
\hline Feb 2019 & -3.27 & (2.19) & & -0.35 & $(0.88)$ & \\
\hline
\end{tabular}




\begin{tabular}{|c|c|c|c|c|c|c|}
\hline Mar 2019 & 0.52 & $(1.92)$ & & -0.23 & $(0.90)$ & \\
\hline Apr 2019 & -1.37 & $(1.92)$ & & -0.27 & $(0.89)$ & \\
\hline May 2019 & -0.41 & $(1.82)$ & & -0.24 & $(0.89)$ & \\
\hline Jun 2019 & -2.15 & (1.75) & & -0.49 & $(0.89)$ & \\
\hline Jul 2019 & -1.85 & (1.79) & & -0.02 & $(0.89)$ & \\
\hline Aug 2019 & -2.41 & (1.75) & & -0.30 & $(0.89)$ & \\
\hline Sep 2019 & -3.29 & (1.71) & $*$ & -0.58 & $(0.88)$ & \\
\hline Oct 2019 & -2.40 & $(1.75)$ & & 0.03 & $(0.89)$ & \\
\hline Nov 2019 & -4.19 & (1.76) & $*$ & -0.51 & $(0.89)$ & \\
\hline Dec 2019 & -2.32 & $(1.77)$ & & -0.06 & $(0.89)$ & \\
\hline $\operatorname{Jan} 2020$ & -2.89 & (1.77) & & 0.37 & $(0.89)$ & \\
\hline Feb 2020 & -2.86 & $(1.88)$ & & 1.40 & $(0.89)$ & \\
\hline Mar 2020 & -2.36 & $(1.89)$ & & 0.26 & $(0.89)$ & \\
\hline Apr 2020 & -13.86 & $(2.05)$ & $* *$ & -1.02 & $(0.88)$ & \\
\hline Industry -- Agriculture & -12.18 & (11.48) & & -0.46 & $(0.42)$ & \\
\hline Industry -- Arts/Entertainment & -18.80 & (10.95) & * & -0.97 & $(0.39)$ & $* *$ \\
\hline Industry -- Business Support & -27.10 & $(11.71)$ & $* *$ & -0.76 & $(0.36)$ & $* *$ \\
\hline Industry -- Construction & -6.94 & (11.12) & & 0.84 & $(0.48)$ & $*$ \\
\hline Industry -- Education & -14.20 & $(11.06)$ & & -0.97 & $(0.41)$ & $* *$ \\
\hline Industry -- Finance and Insurance & -4.81 & $(12.31)$ & & -0.01 & $(1.60)$ & \\
\hline Industry -- Food Services & -15.16 & $(11.13)$ & & -0.27 & $(0.34)$ & \\
\hline Industry -- Health Care & -13.85 & (11.23) & & 0.29 & $(0.36)$ & \\
\hline Industry -- Information & -8.85 & (11.14) & & -0.19 & $(0.51)$ & \\
\hline Industry -- Management & -12.55 & (11.88) & & -0.56 & (1.14) & \\
\hline Industry -- Manufacturing & -8.09 & (11.24) & & 0.00 & $(0.40)$ & \\
\hline Industry -- Mining/Oil/Gas & 4.08 & $(13.02)$ & & -2.53 & $(0.43)$ & $* * *$ \\
\hline Industry -- Other Services & -6.28 & (11.04) & & -0.31 & $(0.37)$ & \\
\hline Industry -- Professional/Scientific & -12.16 & $(11.61)$ & & -0.68 & $(0.43)$ & \\
\hline Industry -- Real Estate & -7.78 & (11.14) & & -0.13 & $(0.47)$ & \\
\hline Industry -- Retail Trade & -10.70 & $(11.23)$ & & -0.28 & $(0.36)$ & \\
\hline Industry -- Trans portation/Storage & -11.14 & (11.54) & & 0.65 & $(0.51)$ & \\
\hline Industry -- Wholesale Trade & -8.53 & (11.24) & & 0.44 & $(0.48)$ & \\
\hline $\mathrm{N}$ & \multicolumn{3}{|c|}{534,779} & \multicolumn{3}{|c|}{534,779} \\
\hline $\mathrm{R} 2$ & \multicolumn{3}{|c|}{0.3718} & \multicolumn{3}{|c|}{0.0159} \\
\hline Mean dependent & \multicolumn{3}{|c|}{55.47} & \multicolumn{3}{|c|}{2.59} \\
\hline
\end{tabular}




\section{Online Appendix Table 1: Coverage of Pension Plans and IRAs among SIPP Survey Respondents}

In this table, we show the fraction of individuals that having a pension plan or an IRA in the sample of the Survey of Income and Program Participation (SIPP). Data come from the 2014 Social Security Administration Supplement Data, which is part of the 2014 Survey of Income and Program Participation (SIPP). Panel A shows the percent of SIPP survey respondents not included in an employment-based pension plan. Pension Plans include defined-benefit plans, 401(k)s, and 403(b)s. About 30\% of SIPP respondents did not have access to an employment-based pension plan in 2014. Panel B presents, of all workers without access to an employment-based pension plan, $7.5 \%$ of workers had an IRA and were actively contributing to their IRA account. Another $14.5 \%$ of workers had an IRA but were not actively contributing. About $78 \%$ of workers did not have a pension plan or an IRA. Panel C compares selected socioeconomic characteristics between workers covered by OregonSaves and SIPP respondents not included in a pension plan. The average age for both groups is 37. Average monthly earnings are \$2,887 (before-tax) for OregonSaves workers and $\$ 2,933$ (before-tax) for SIPP respondents lacking access to a pension plan. Pre-tax earnings for OregonSaves workers are computed using the after-tax earnings imputed from the OregonSaves data, the marginal federal tax rate in 2019, and the marginal state tax rate in Oregon in 2019. Monthly earnings are more volatile for OregonSaves workers than SIPP respondents. Following the previous literature summarized in Hannagan and Morduch (2015), we calculate income volatility as the standard deviation of monthly earnings divided by average monthly earnings. Previous studies found that the income volatility measure is usually between 0.15 and 0.45 . To calculate the income volatility for OregonSaves workers who still participated in the OS program in April 2020, we use their imputed monthly earnings records in 2019 to minimize the impact of the COVID-19 on income volatility in 2020. For SIPP respondents, we use their monthly earnings in 2014 reported in the SIPP survey. Source: Authors calculations.

Panel A: Percent of SIPP survey respondents not included in a pension plan (including definedbenefit plans, $401(\mathrm{k}) \mathrm{s}, 403(\mathrm{~b}) \mathrm{s}$, etc.)

\begin{tabular}{c|rr} 
& $\mathrm{N}$ & Percent \\
Included in a plan & 6,928 & 70 \\
Not included & 2,963 & 30 \\
\hline Total & 9,891 & 100
\end{tabular}

Panel B: Of all workers not included in a pension plan, percent of workers having an IRA

\begin{tabular}{c|rr} 
& $\mathrm{N}$ & Percent \\
With an IRA \& actively contributing & 224 & 7.5 \\
With an IRA but not actively contributing & 432 & 14.5 \\
Without an IRA & 2,307 & 78 \\
\hline Total & 2,963 & 100
\end{tabular}

Panel C: Comparison of socioeconomic characteristics between workers having access to OregonSaves and workers not included in a pension plan in the SIPP sample

\begin{tabular}{c|rr} 
& OregonSaves workers & $\begin{array}{r}\text { SIPP workers not included } \\
\text { in a pension plan }\end{array}$ \\
\hline Year & 2020 & 2014 \\
Sample size & 289,657 & 2,963 \\
Average age & 37 & 37 \\
Average monthly pre-tax earnings & 2,887 & 2,933 \\
(in 2020 dollars) & & 0.16 \\
Income volatility & 0.40 &
\end{tabular}




\section{Online Appendix Table 2: OregonSaves Opt-Out Rates Over Time}

In this table, the unit of observation is employee $i$ in the initial month in which the employee would be eligible to contribute into OregonSaves (where the eligibility date is set under the assumptions that her identify is verified and she remains employed) and over the following twelve months. We report opt out rates for the full sample of employees for whom we possess data in month $\mathrm{t}$, and separately for employees for whom accounts were and were not opened. Differences across account status reflect the fact that formally opting out of OregonSaves reduces the likelihood that an account is ever opened. Note that the $40.9 \%$ overall opt out rate in month three matches the full-sample rate in the bottom row of Table 3. Source: Authors calculations.

\begin{tabular}{rccr}
\hline Months \\
since \\
\cline { 2 - 3 } eligibility & \multicolumn{3}{c}{ Fraction of employees who formally opt out } \\
\cline { 2 - 3 } 0 & \multicolumn{2}{c}{ Account open? } & Yes \\
1 & $58.2 \%$ & $24.7 \%$ & $34.1 \%$ \\
2 & $59.9 \%$ & $30.4 \%$ & $38.6 \%$ \\
3 & $60.1 \%$ & $32.1 \%$ & $39.9 \%$ \\
4 & $60.8 \%$ & $33.3 \%$ & $40.9 \%$ \\
5 & $60.3 \%$ & $33.5 \%$ & $41.0 \%$ \\
6 & $58.7 \%$ & $33.3 \%$ & $40.3 \%$ \\
7 & $58.3 \%$ & $33.6 \%$ & $40.1 \%$ \\
8 & $58.5 \%$ & $34.3 \%$ & $40.4 \%$ \\
9 & $59.5 \%$ & $35.2 \%$ & $41.1 \%$ \\
10 & $59.8 \%$ & $35.8 \%$ & $41.5 \%$ \\
11 & $60.0 \%$ & $36.0 \%$ & $41.6 \%$ \\
12 & $58.2 \%$ & $35.8 \%$ & $40.9 \%$ \\
All & $57.8 \%$ & $35.9 \%$ & $40.7 \%$ \\
& $59.3 \%$ & $33.1 \%$ & $39.9 \%$ \\
\hline
\end{tabular}




\section{Online Appendix Table 3: OregonSaves Opt-Out Rates by Month}

In this table, the unit of observation is employee $i$ three months after the data on which the employee would be eligible to contribute into OregonSaves (under the assumptions that she has her identify verified and remains employed). We exclude employees who become eligible before July 2018 (because we lack data on the timing of opt out before August 2018) or after January 2020 (because the administrative data end in April 2020). We exclude the small number of employees for whom an eligibility date is missing (typically because the employer is classified as "Exempt"). We do not condition on the employee being classified as active or having an open account. Note that the $40.9 \%$ overall opt out rate matches the rate in the bottom row of Table 3. Source: Authors calculations; see text.

\begin{tabular}{rrrr}
\hline & \multicolumn{3}{c}{ Formally opt out within three months of eligibility? } \\
\cline { 2 - 4 } Date & No & Yes & $\%$ Yes \\
Aug 2018 & 4,409 & 3,167 & $41.8 \%$ \\
Sep 2018 & 4,615 & 3,195 & $40.9 \%$ \\
Oct 2018 & 4,381 & 2,770 & $38.7 \%$ \\
Nov 2018 & 4,126 & 2,118 & $33.9 \%$ \\
Dec 2018 & 3,542 & 1,528 & $30.1 \%$ \\
Jan 2019 & 3,351 & 1,140 & $25.4 \%$ \\
Feb 2019 & 3,512 & 1,852 & $34.5 \%$ \\
Mar 2019 & 4,926 & 2,698 & $35.4 \%$ \\
Apr 2019 & 9,610 & 7,587 & $44.1 \%$ \\
May 2019 & 8,394 & 6,149 & $42.3 \%$ \\
Jun 2019 & 4,528 & 2,946 & $39.4 \%$ \\
Jul 2019 & 5,624 & 2,408 & $30.0 \%$ \\
Aug 2019 & 6,147 & 4,789 & $43.8 \%$ \\
Sep 2019 & 11,799 & 9,992 & $45.9 \%$ \\
Oct 2019 & 9,870 & 6,046 & $38.0 \%$ \\
Nov 2019 & 6,606 & 3,732 & $36.1 \%$ \\
Dec 2019 & 6,216 & 3,544 & $36.3 \%$ \\
Jan 2020 & 5,697 & 3,361 & $37.1 \%$ \\
Feb 2020 & 6,166 & 4,996 & $44.8 \%$ \\
Mar 2020 & 9,061 & 9,116 & $50.2 \%$ \\
Apr 2020 & 8,722 & 7,679 & $46.8 \%$ \\
All & 131,302 & 90,813 & $40.9 \%$ \\
\hline
\end{tabular}




\section{Online Appendix Table 4: Likelihood of Increasing or Decreasing Contribution Rate, by Month}

In this table, we report the fractions of employees who have not formally opted out of OregonSaves in month $t-1$ that (a) increase their contribution rate in month $t$, decrease their contribution rate in month $t$ without formally opting out, and decreasing their contribution rate in month $t$ by formally opting out. We do not impose any other filters on the sample. Because our contribution rate date begins in August 2018, the first month for which we can measure changes is September 2018. The vast majority of the increases in January 2019 and January 2020 are due to automatic escalation. Source: Authors calculations; see text.

\begin{tabular}{rrrr}
\hline & $\begin{array}{r}\text { Decrease } \\
\text { Increase } \\
\text { rate }\end{array}$ & $\begin{array}{r}\text { Decrease } \\
\text { rate without } \\
\text { opting out }\end{array}$ & $\begin{array}{r}\text { rate by } \\
\text { opting out }\end{array}$ \\
Sep 2018 & $0.1 \%$ & $1.0 \%$ & $2.6 \%$ \\
Oct 2018 & $0.1 \%$ & $1.7 \%$ & $2.2 \%$ \\
Nov 2018 & $0.1 \%$ & $1.1 \%$ & $2.6 \%$ \\
Dec 2018 & $0.1 \%$ & $0.3 \%$ & $3.9 \%$ \\
Jan 2019 & $12.9 \%$ & $0.4 \%$ & $7.8 \%$ \\
Feb 2019 & $0.1 \%$ & $0.4 \%$ & $5.7 \%$ \\
Mar 2019 & $0.1 \%$ & $0.2 \%$ & $3.3 \%$ \\
Apr 2019 & $0.1 \%$ & $0.2 \%$ & $2.6 \%$ \\
May 2019 & $0.1 \%$ & $0.2 \%$ & $3.6 \%$ \\
Jun 2019 & $0.1 \%$ & $0.3 \%$ & $5.4 \%$ \\
Jul 2019 & $0.1 \%$ & $0.2 \%$ & $4.2 \%$ \\
Aug 2019 & $0.1 \%$ & $0.3 \%$ & $2.6 \%$ \\
Sep 2019 & $0.1 \%$ & $0.2 \%$ & $2.6 \%$ \\
Oct 2019 & $0.1 \%$ & $0.2 \%$ & $2.1 \%$ \\
Nov 2019 & $0.1 \%$ & $0.3 \%$ & $2.5 \%$ \\
Dec 2019 & $0.1 \%$ & $0.5 \%$ & $4.1 \%$ \\
Jan 2020 & $14.2 \%$ & $1.1 \%$ & $4.2 \%$ \\
Feb 2020 & $0.1 \%$ & $0.3 \%$ & $2.1 \%$ \\
Mar 2020 & $0.0 \%$ & $0.4 \%$ & $1.7 \%$ \\
Apr 2020 & $0.0 \%$ & $0.5 \%$ & $0.7 \%$ \\
All & $1.5 \%$ & $0.4 \%$ & $3.1 \%$ \\
\hline
\end{tabular}


Online Appendix Table 5: Aggregate Asset Allocation Snapshots, August 2018 - April 2020

In this table, we report the aggregate number of dollars invested in each investment option on four different dates: August 2018, December 2018, December 2019, and April 2020. The State Street Target Retirement 2015 Fund merged into State Street Target Retirement Fund during March 2020. The State Street Target Retirement 2070 Fund was added during April 2020. Source: Authors calculations; see text.

\begin{tabular}{|c|c|c|c|c|c|c|c|c|}
\hline \multirow[b]{2}{*}{ Fund Name } & \multicolumn{2}{|c|}{ August 2018} & \multicolumn{2}{|c|}{ December 2018} & \multicolumn{2}{|c|}{ December 2019} & \multicolumn{2}{|c|}{ April 2020} \\
\hline & $\$$ million & $\%$ & $\$$ million & $\%$ & $\$$ million & $\%$ & $\$$ million & $\%$ \\
\hline State Street Institutional Liquid Reserve Fund & 5.77 & $86.3 \%$ & 8.66 & $79.0 \%$ & 26.68 & $65.1 \%$ & 29.66 & $58.1 \%$ \\
\hline State Street Target Retirement Fund & 0.01 & $0.1 \%$ & 0.02 & $0.2 \%$ & 0.22 & $0.5 \%$ & 0.64 & $1.2 \%$ \\
\hline State Street Target Retirement 2015 Fund & 0.02 & $0.3 \%$ & 0.05 & $0.5 \%$ & 0.26 & $0.6 \%$ & 0.00 & \\
\hline State Street Target Retirement 2020 Fund & 0.05 & $0.7 \%$ & 0.12 & $1.1 \%$ & 0.63 & $1.5 \%$ & 0.94 & $1.8 \%$ \\
\hline State Street Target Retirement 2025 Fund & 0.08 & $1.3 \%$ & 0.22 & $2.0 \%$ & 1.19 & $2.9 \%$ & 1.74 & $3.4 \%$ \\
\hline State Street Target Retirement 2030 Fund & 0.10 & $1.5 \%$ & 0.25 & $2.3 \%$ & 1.46 & $3.6 \%$ & 2.24 & $4.4 \%$ \\
\hline State Street Target Retirement 2035 Fund & 0.13 & $2.0 \%$ & 0.30 & $2.8 \%$ & 1.67 & $4.1 \%$ & 2.47 & $4.8 \%$ \\
\hline State Street Target Retirement 2040 Fund & 0.11 & $1.6 \%$ & 0.27 & $2.4 \%$ & 1.55 & $3.8 \%$ & 2.27 & $4.5 \%$ \\
\hline State Street Target Retirement 2045 Fund & 0.12 & $1.7 \%$ & 0.28 & $2.6 \%$ & 1.68 & $4.1 \%$ & 2.57 & $5.0 \%$ \\
\hline State Street Target Retirement 2050 Fund & 0.10 & $1.6 \%$ & 0.29 & $2.6 \%$ & 1.87 & $4.6 \%$ & 2.77 & $5.4 \%$ \\
\hline State Street Target Retirement 2055 Fund & 0.06 & $1.0 \%$ & 0.22 & $2.0 \%$ & 1.62 & $4.0 \%$ & 2.62 & $5.1 \%$ \\
\hline State Street Target Retirement 2060 Fund & 0.03 & $0.5 \%$ & 0.13 & $1.2 \%$ & 1.20 & $2.9 \%$ & 1.84 & $3.6 \%$ \\
\hline State Street Target Retirement 2065 Fund & 0.01 & $0.1 \%$ & 0.02 & $0.2 \%$ & 0.25 & $0.6 \%$ & 0.43 & $0.8 \%$ \\
\hline State Street Target Retirement 2070 Fund & & & & & & & 0.00 & $0.0 \%$ \\
\hline State Street Equity 500 Index Fund & 0.09 & $1.3 \%$ & 0.12 & $1.1 \%$ & 0.71 & $1.7 \%$ & 0.91 & $1.8 \%$ \\
\hline Total & 6.69 & $100.0 \%$ & 10.96 & $100.0 \%$ & 40.99 & $100.0 \%$ & 51.09 & $100.0 \%$ \\
\hline Funds other than Liquid Reserve & 0.92 & $13.7 \%$ & 2.30 & $21.0 \%$ & 14.30 & $34.9 \%$ & 21.43 & $41.9 \%$ \\
\hline
\end{tabular}


Online Appendix Table 6: Fund Returns and Flows, August 2018 - April 2020

In this table, we report summary statistics for the investment options available through OregonSaves. The unit of observation is fund $\mathrm{i}$ in month $\mathrm{t}$ and the sample is limited to the period August 2018 to April 2020. The outflows from the State Street Institutional Liquid Reserve Fund in February 2020 are driven by exchanges into the target retirement funds. The State Street Target Retirement 2015 Fund merged into State Street Target Retirement Fund during March 2020. The State Street Target Retirement 2070 Fund was added during April 2020. Source: Authors calculations; see text.

\begin{tabular}{|c|c|c|c|c|c|c|c|c|c|}
\hline \multirow[b]{2}{*}{ Fund Name } & \multirow[b]{2}{*}{ Fund_key } & \multicolumn{4}{|c|}{ Monthly return } & \multicolumn{4}{|c|}{ Monthly net flow (\% lagged AUM) } \\
\hline & & Average & Std. dev. & Minimum & Maximum & Average & Std. dev. & Minimum & Maximum \\
\hline State Street Institutional Liquid Reserve Fund & 10013 & $0.10 \%$ & $0.07 \%$ & $-0.10 \%$ & $0.20 \%$ & $8.9 \%$ & $4.0 \%$ & $-1.8 \%$ & $16.7 \%$ \\
\hline State Street Target Retirement Fund & 10000 & $0.26 \%$ & $2.40 \%$ & $-6.31 \%$ & $5.00 \%$ & $19.8 \%$ & $19.0 \%$ & $6.2 \%$ & $91.4 \%$ \\
\hline State Street Target Retirement 2015 Fund & 10001 & $0.36 \%$ & $1.75 \%$ & $-3.23 \%$ & $4.08 \%$ & $17.7 \%$ & $14.9 \%$ & $4.0 \%$ & $63.0 \%$ \\
\hline State Street Target Retirement 2020 Fund & 10002 & $0.22 \%$ & $3.19 \%$ & $-8.28 \%$ & $6.24 \%$ & $17.0 \%$ & $8.4 \%$ & $5.9 \%$ & $35.0 \%$ \\
\hline State Street Target Retirement 2025 Fund & 10003 & $0.26 \%$ & $3.77 \%$ & $-9.18 \%$ & $7.63 \%$ & $17.6 \%$ & $9.4 \%$ & $6.8 \%$ & $42.0 \%$ \\
\hline State Street Target Retirement 2030 Fund & 10004 & $0.28 \%$ & $4.15 \%$ & $-9.70 \%$ & $8.46 \%$ & $17.9 \%$ & $8.7 \%$ & $8.4 \%$ & $40.3 \%$ \\
\hline State Street Target Retirement 2035 Fund & 10005 & $0.23 \%$ & $4.52 \%$ & $-10.56 \%$ & $9.12 \%$ & $16.8 \%$ & $8.1 \%$ & $8.4 \%$ & $39.1 \%$ \\
\hline State Street Target Retirement 2040 Fund & 10006 & $0.18 \%$ & $4.88 \%$ & $-11.44 \%$ & $9.61 \%$ & $18.0 \%$ & $9.8 \%$ & $7.6 \%$ & $45.8 \%$ \\
\hline State Street Target Retirement 2045 Fund & 10007 & $0.13 \%$ & $5.21 \%$ & $-12.39 \%$ & $10.12 \%$ & $18.2 \%$ & $9.4 \%$ & $8.2 \%$ & $43.4 \%$ \\
\hline State Street Target Retirement 2050 Fund & 10008 & $0.12 \%$ & $5.33 \%$ & $-12.77 \%$ & $10.39 \%$ & $19.4 \%$ & $10.6 \%$ & $7.9 \%$ & $43.9 \%$ \\
\hline State Street Target Retirement 2055 Fund & 10009 & $0.11 \%$ & $5.28 \%$ & $-12.75 \%$ & $10.27 \%$ & $23.0 \%$ & $15.2 \%$ & $9.1 \%$ & $64.4 \%$ \\
\hline State Street Target Retirement 2060 Fund & 10010 & $0.12 \%$ & $5.29 \%$ & $-12.76 \%$ & $10.18 \%$ & $25.0 \%$ & $15.8 \%$ & $8.5 \%$ & $63.7 \%$ \\
\hline State Street Target Retirement 2065 Fund & 10011 & $0.18 \%$ & $5.41 \%$ & $-12.68 \%$ & $11.46 \%$ & $23.0 \%$ & $7.2 \%$ & $13.1 \%$ & $36.6 \%$ \\
\hline State Street Target Retirement 2070 Fund & 10600 & & & & & & & & \\
\hline State Street Equity 500 Index Fund & 10012 & $0.43 \%$ & $6.09 \%$ & $-12.47 \%$ & $12.79 \%$ & $12.9 \%$ & $4.7 \%$ & $2.5 \%$ & $22.1 \%$ \\
\hline
\end{tabular}




\section{Online Appendix Table 7: Dispersion of OregonSaves Account Balances Based on Employee Status}

In this table, the unit of observation is account $i$ in month $t$. We limit the sample to accounts for which the first contribution is August 2018 or later (which explains why the number of open accounts in the first column is less than 70,077). We begin following an account when it makes its first contribution into OregonSaves and then track the account forward up to 18 months. Because the number of OregonSaves participants is growing over time, we necessarily have fewer observations as we move from month $\mathrm{t}$ of the initial contribution to month $t+17$. The fraction of participants classified by (one or more of their employers) as active at the end of month $t$ falls from $96.8 \%$ to $61.5 \%$. We report the 10th, 25th, 50th, 75th, and 90th percentiles of OregonSaves account balance separately for active and inactive employees. Source: Authors calculations; see text.

\begin{tabular}{|c|c|c|c|c|c|c|c|c|c|c|c|c|}
\hline \multirow{3}{*}{$\begin{array}{r}\text { Months } \\
\text { since initial } \\
\text { contribution }\end{array}$} & \multirow{3}{*}{$\begin{array}{l}\text { Number } \\
\text { of open } \\
\text { accounts }\end{array}$} & \multirow{3}{*}{$\begin{array}{l}\% \text { still } \\
\text { active }\end{array}$} & \multicolumn{10}{|c|}{ Account balance percentile } \\
\hline & & & \multicolumn{5}{|c|}{ Employee classified as active in month $\mathrm{t}$} & \multicolumn{5}{|c|}{ Employee classified as inactive in month $\mathrm{t}$} \\
\hline & & & 10th & 25th & 50th & 75th & $\overline{90 \text { th }}$ & 10th & 25th & 50th & 75th & 90th \\
\hline 1 & 59,043 & $96.8 \%$ & 15 & 32 & 59 & 106 & 176 & 8 & 22 & 49 & 99 & 180 \\
\hline 2 & 57,547 & $93.3 \%$ & 26 & 66 & 132 & 220 & 343 & 10 & 29 & 63 & 125 & 224 \\
\hline 3 & 55,332 & $90.0 \%$ & 31 & 91 & 201 & 336 & 515 & 9 & 32 & 75 & 160 & 300 \\
\hline 4 & 52,179 & $86.5 \%$ & 31 & 107 & 268 & 452 & 693 & 9 & 36 & 92 & 200 & 360 \\
\hline 5 & 47,559 & $83.6 \%$ & 28 & 115 & 324 & 567 & 868 & 7 & 37 & 100 & 226 & 411 \\
\hline 6 & 43,885 & $81.0 \%$ & 25 & 120 & 376 & 681 & 1,050 & 6 & 38 & 109 & 257 & 468 \\
\hline 7 & 41,320 & $79.0 \%$ & 22 & 121 & 422 & 790 & 1,223 & 4 & 38 & 115 & 282 & 521 \\
\hline 8 & 38,558 & $76.9 \%$ & 19 & 120 & 465 & 899 & 1,393 & 2 & 38 & 122 & 297 & 569 \\
\hline 9 & 35,621 & $75.2 \%$ & 15 & 116 & 500 & 1,006 & 1,559 & 0 & 39 & 130 & 321 & 631 \\
\hline 10 & 31,856 & $73.6 \%$ & 12 & 112 & 528 & 1,099 & 1,720 & 0 & 40 & 139 & 349 & 693 \\
\hline 11 & 27,332 & $71.6 \%$ & 10 & 108 & 557 & 1,196 & 1,907 & 0 & 38 & 143 & 372 & 741 \\
\hline 12 & 23,617 & $69.9 \%$ & 6 & 103 & 580 & 1,287 & 2,063 & 0 & 37 & 144 & 388 & 775 \\
\hline 13 & 21,190 & $68.8 \%$ & 4 & 100 & 595 & 1,372 & 2,208 & 0 & 35 & 146 & 407 & 798 \\
\hline 14 & 18,627 & $67.6 \%$ & 0 & 96 & 607 & 1,463 & 2,361 & 0 & 34 & 147 & 430 & 864 \\
\hline 15 & 15,178 & $65.3 \%$ & 2 & 96 & 634 & 1,560 & 2,549 & 0 & 33 & 145 & 446 & 940 \\
\hline 16 & 11,211 & $65.0 \%$ & 0 & 89 & 627 & 1,620 & 2,684 & 0 & 31 & 142 & 448 & 948 \\
\hline 17 & 7,714 & $63.7 \%$ & 0 & 71 & 555 & 1,609 & 2,767 & 0 & 28 & 131 & 438 & 989 \\
\hline 18 & 6,053 & $61.5 \%$ & 0 & 86 & 621 & 1,729 & 2,855 & 0 & 29 & 140 & 455 & 1,009 \\
\hline
\end{tabular}

